\begin{tabular}{|c|c|c|c|}
\hline $\begin{array}{l}\text { Submission: } 24 / \mathrm{Jan} / 2021 \text {; } \\
\text { Camera ready: } 13 / \mathrm{Jul} / 2021 \text {; }\end{array}$ & $\begin{array}{l}1^{\text {st }} \text { round notif.: 05/May/2021; } \\
\text { Edition review: } 21 / \mathrm{Jul} / 2021 \text {; }\end{array}$ & $\begin{array}{l}\text { New version: } 24 / \mathrm{Mai} / 2021 ; \\
\text { Available online: } 06 / \mathrm{Aug} / 2021 \text {; }\end{array}$ & $\begin{array}{l}2^{\text {nd }} \text { round notif:: } 30 / \mathrm{Jun} / 2021 \text {; } \\
\text { Published: 06/Aug/2021; }\end{array}$ \\
\hline
\end{tabular}

\title{
Avaliando um Aplicativo Android Para Apoiar a Aplicação de Exercícios de Computação Desplugada
}

\author{
Title: Evaluating an Android Application to Support the Application of Unplugged \\ Computing Exercises
}

\author{
Matheus Barbosa de Oliveira \\ UFPE - Universidade Federal de Pernambuco \\ UFPB - Universidade Federal da Paraíba \\ matheus.barbosa@dcx.ufpb.br
}

\author{
Ayla Débora Dantas de Souza Rebouças \\ UFPB - Universidade Federal da Paraíba \\ ayla@dcx.ufpb.br
}

\begin{abstract}
Resumo
Esse artigo tem como objetivo apresentar uma avaliação do "Computação Plugada", um aplicativo Android desenvolvido com o intuito de tornar mais fácil a disseminação de atividades de computação desplugada, proporcionando assim aos seus usuários o desenvolvimento de habilidades relacionadas ao pensamento computacional. A ideia do aplicativo é que possa simplificar a aplicação dessas atividades em sala de aula, mas que também permita que usuários consigam individualmente realizar essas atividades recebendo feedback automático. Foram disponibilizados questionários online para estudantes e para professores de computação que já possuíam experiência com computação desplugada. Também foi realizada uma observação espontânea buscando identificar alguns aspectos como interesse e colaboração dos alunos de três turmas do primeiro ano do ensino médio submetidos à utilização do aplicativo em sala de aula e foi feita uma entrevista semiestruturada com a professora das turmas. Os resultados apresentados dão indícios de que o aplicativo pode ser adequado para utilização individual ou em sala de aula. Observou-se que a aplicação em sala de aula com o compartilhamento de dispositivos pode favorecer a interação entre os estudantes e a aprendizagem colaborativa, além de poder facilitar a aplicação de atividades que estimulam o desenvolvimento do pensamento computacional.
\end{abstract}

Palavras-Chave: Computação Desplugada; Pensamento Computacional; Educação em Computação.

\begin{abstract}
This article aims to present an evaluation of "Computação Plugada", an Android application developed with the purpose of making easier the dissemination of unplugged computing activities, thus giving its users the development of skills related to computational thinking. The idea of the application is that it can simplify the application of these activities in the classroom. However, it can also allow individual users to accomplish these activities by receiving automatic feedback. Online questionnaires were sent to students and to computer science teachers who already had experience with unplugged computing. We have also performed a spontaneous observation. Its purpose was to identify some aspects such as interest and collaboration of the students of three classes of the first year of high school submitted to the use of the application in the classroom. There was also a semistructured interview with the teacher. The results presented give evidence that the application may be suitable for individual or classroom use. We have observed that its use in the classroom may lead to more interaction between the students and to collaborative learning. Besides, it seems to be an easier way to apply activities that stimulate computational thinking.
\end{abstract}

Keywords: Unplugged Computing; Computational Thinking; Computer Science Education.

Cite as: Oliveira, M. B., \& Rebouças, A. D. D. S. (2021). Avaliando um Aplicativo Android Para Apoiar a Aplicação de Exercícios de Computação Desplugada. Revista Brasileira de Informática na Educação, 29, 798-826. 


\section{Introdução}

A internet e os dispositivos móveis estão cada vez mais presentes no nosso cotidiano. Considerando este aspecto, as escolas sentem a necessidade de atualização e de mudanças em seus paradigmas e métodos, pois alguns alunos vivenciam as constantes inovações tecnológicas no mesmo compasso em que elas ocorrem (Silvestrin, 2018). Vê-se também que as tecnologias digitais podem ser utilizadas para aprender em qualquer lugar, tempo e de múltiplas formas (Moran, 2007) e que podem inclusive ser utilizadas para aprender sobre a própria computação ou para desenvolver o Pensamento Computacional (PC).

Segundo Wing (2014), o PC é o processo de pensamento envolvido na formulação de um problema e na expressão de sua solução de forma que um computador - humano ou máquina possa efetivamente realizá-la. O Pensamento Computacional envolve assim um conjunto de habilidades e competências relacionadas ao processo de resolução de problemas e que são relevantes para pessoas de qualquer que seja a área. A própria Base Nacional Comum Curricular (BNCC) reconhece a importância do Pensamento Computacional e do desenvolvimento de habilidades como Decomposição, Reconhecimento de Padrões, Abstração e Algoritmos, conforme se pode observar no Currículo de Referência em Tecnologia e Computação - CIEB ${ }^{1}$.

Embora existam diferentes métodos e ferramentas para apoiar o desenvolvimento do pensamento computacional, como AppInventor, ${ }^{2} \mathrm{Code}_{\text {org }}{ }^{3}, \mathrm{Scratch}^{4}$, KTurtle ${ }^{5}$, este trabalho tomará como foco atividades da Computação Desplugada e uma ferramenta inspirada nessas atividades, que é o aplicativo "Computação Plugada". Este aplicativo é apresentado no trabalho de Oliveira et al. (2019) e está disponível no site $^{6}$ do projeto Computação Plugada da UFPB.

Conforme destacam Bell et al. (2009), atividades da computação desplugada são atividades que envolvem resolução de problemas sem o uso de computadores e onde durante esse processo de alcançar um objetivo se lida com conceitos fundamentais da Ciência da Computação. Algumas dessas atividades são baseadas em conceitos matemáticos, como o entendimento dos números binários, e há também as que são relacinadas à área de tecnologia, como atividades que ajudam na compreensão sobre o funcionamento dos computadores, conforme se pode observar no livro de Bell et al. (2011).

É importante ressaltar, porém, que alguns pesquisadores, mesmo reconhecendo a eficiência da computação desplugada, destacam a importância de "plugar" os alunos, como é o caso de Kafai e Burke (2014), ao discutir sobre ensino de computação com programação e onde chamam a atenção para a redescoberta do computador como um meio para conectividade pessoal e social. Os autores Berto, Zaina e Sakata (2019), destacam em seu trabalho que o uso de atividades de diferentes formatos, como plugadas e desplugadas, possibilita ao aluno diversas maneiras de explorar o conhecimento e colocá-lo em prática. Por exemplo, explorar apenas atividades desplugadas pode não ser interessante para alguns estudantes. Além disso, a preparação dessas atividades com diferentes materiais pode demandar muito tempo do professor, sendo, portanto, relevante analisar se aplicativos para dispositivos móveis baseados nessas atividades podem ser

\footnotetext{
${ }^{1}$ Currículo de Referência em Tecnologia e Computação - CIEB." http://curriculo.cieb.net.br/. Acessado em 26 out. 2020.

2 "MIT App Inventor." 31 jan. 2019, http://appinventor.mit.edu/. Acessado em 21 fev. 2019.

3 "Code.org." https://code.org/. Acessado em 21 fev. 2019.

4 "Scratch - Imagine, Program, Share - MIT." https://scratch.mit.edu/. Acessado em 21 fev. 2019.

5 "The KDE Education Project - KTurtle." https://edu.kde.org/kturtle/. Acessado em 21 fev. 2019.

6 "Computação Plugada." https://sites.google.com/view/computacaoplugada/download. Acessado em 26 out.. 2020.
} 
uma boa estratégia, visto que poderiam apoiar também no processo de feedback, que pode ser difícil de ser oferecido em turmas grandes.

Conforme destacado no trabalho de Oliveira et al. (2019), considerando que grande parte das pessoas já possui dispositivos móveis e demonstram interesse em utilizá-los, buscou-se no trabalho explorar tais dispositivos no intuito de apoiar a realização de atividades da computação desplugada que levem à disseminação de conceitos da computação, como números binários. Para isso, os autores propuseram o aplicativo "Computação Plugada". No entanto, no trabalho não foi apresentada avaliação da ferramenta e foi dado um foco em sua descrição.

O presente artigo tem como objetivo avaliar sob o ponto de vista de professores e alunos como se dá o uso e a aceitação do aplicativo "Computação Plugada" como uma forma alternativa para apoiar o ensino e aprendizagem em computação, e mais especificamente de números binários e que foi projetado com base no livro de Bell et al. (2011). De maneira geral, este trabalho buscou responder a seguinte questão de pesquisa: "Como se dá a aceitação da utilização de um aplicativo Android com exercícios da computação desplugada por professores de computação e por alunos?"

A metodologia proposta para atingir o objetivo apresentado envolve um estudo observacional com fins de avaliação de uma ferramenta e levantamento de dados com questionários, caracterizando-se assim como uma pesquisa qualitativa e quantitativa. Foram aplicados questionários online com professores de computação buscando identificar a percepção de aplicabilidade do aplicativo através da visão desses profissionais. Também foram aplicados questionários online com estudantes que utilizaram o aplicativo de maneira autônoma. Os questionários eram compostos por perguntas sobre usabilidade, percepção de aprendizagem e aceitação do uso do aplicativo. Algumas perguntas dos questionários aplicados fazem parte do questionário Self Assessment Manikin (SAM), desenvolvido por Bradley e Lang (1994). O SAM, segundo os autores, é uma técnica de avaliação representada por imagens e que mede diretamente a satisfação, a motivação e o sentimento de controle associado ao caráter afetivo de uma pessoa. Além disso, foi realizado um estudo em três turmas do ensino médio, explorando a utilização do aplicativo "Computação Plugada" com atividades propostas pelo livro" "Computer Science Unplugged" (em português - Computação Desplugada) de Tim Bell, Lan H. Witten e Mike Fellows onde os alunos foram divididos em duplas ou trios para utilizar o aplicativo. Os alunos também responderam o mesmo questionário destinado aos estudantes que utilizaram o aplicativo de maneira autônoma. Ao fim das atividades, foi realizada uma entrevista com a professora responsável por aplicar as atividades com os alunos.

As demais seções deste trabalho estão organizadas conforme descrito a seguir. A Seção 2 apresenta a fundamentação teórica deste trabalho, com conceitos fundamentais sobre o Pensamento Computacional, a computação desplugada e os métodos de avaliação utilizados na pesquisa. Já na Seção 3 encontram-se os trabalhos relacionados com as principais semelhanças e diferenças com relação a este trabalho. A Seção 4 descreve a metodologia e as atividades desenvolvidas. A Seção 5 apresenta o aplicativo Computação Plugada, alguns detalhes do seu desenvolvimento e a descrição das atividades contidas nele. Já na Seção 6 são demonstrados os resultados com base nos dados obtidos nas respostas dos questionários de avaliação do aplicativo, na observação da execução das atividades com o aplicativo em sala de aula e da entrevista

\footnotetext{
7 "Ensinando Ciência da Computação sem o uso do computador." https://classic.csunplugged.org/wpcontent/uploads/2014/12/CSUnpluggedTeachers-portuguese-brazil-feb-2011.pdf. Acessado em 30 out. 2020.
} 
realizada com a professora responsável pela aplicação. Por fim, na Seção 7 estão apresentadas as considerações finais e as sugestões de trabalhos futuros.

\section{Fundamentação Teórica}

Nesta seção serão detalhados alguns fundamentos do pensamento computacional, da computação desplugada e da avaliação da experiência do usuário, para facilitar a compreensão dos resultados obtidos.

\subsection{Pensamento Computacional}

O Pensamento Computacional, conforme destacado por Wing (2006), é uma habilidade fundamental para todos, comparada a ler, escrever ou realizar operações matemáticas. O Pensamento Computacional envolve resolver problemas, projetar sistemas e compreender comportamento e se baseia nos conceitos fundamentais à ciência da computação.

A Google for Education ${ }^{8}$ define o PC como um processo de resolução de problemas que inclui várias características, como ordenar e analisar logicamente dados e criar soluções usando uma série de etapas ordenadas (ou algoritmos) e disposições, como a capacidade de lidar com a complexidade e problemas em aberto.

Brackmann et al. (2017) destaca que o Pensamento Computacional baseia-se em quatro pilares: Decomposição, Reconhecimento de Padrões, Abstração e Algoritmo, que podem ser definidos da seguinte forma: i) Decomposição: Identificar um problema complexo e quebrá-lo em partes menores e mais fáceis de gerenciar; ii) Reconhecimento de padrões: Através da análise individual dos problemas menores com maior profundidade se pode identificar problemas parecidos que já foram solucionados anteriormente; iii) Abstração: Foco apenas nos detalhes que são importantes, enquanto informações irrelevantes são ignoradas; iv) Algoritmos: Passos ou regras simples que podem ser criados para resolver cada um dos subproblemas encontrados. Esses elementos são independentes entre si e possuem grande importância quanto ao objetivo principal do PC que é melhorar a capacidade para resolução de problemas.

Há diferentes estratégias para estimular as habilidades do pensamento computacional, sendo uma delas o ensino de programação, pois conforme destacam Berto, Zaina e Sakata (2019), a elaboração de uma solução computacional desenvolve intrinsecamente 0 raciocínio computacional, pois requer uma série de procedimentos mentais. Uma outra estratégia é a utilização de atividades da Computação Desplugada. Conforme destacado por Brackman et al. (2017), com o uso de atividades desplugadas (sem a necessidade de máquinas), é possível ensinar PC de maneira mais acessível, explorando materiais como papel, tesoura, canetas e lápis de colorir. Há na literatura vários trabalhos abordando essas estratégias e avaliando-as. Os principais instrumentos e artefatos que avaliam as habilidades do pensamento computacional no Brasil são testes e códigos/projetos, conforme discutido por Araújo, Andrade e Guerrero (2016).

\subsection{Computação Desplugada}

A computação desplugada consiste em um conjunto de atividades desenvolvidas com o objetivo de ensinar os fundamentos da Ciência da Computação sem a necessidade de computadores, conforme detalha Bell et al. (2011). Essas atividades são desenvolvidas de maneira lúdica e intuitiva e não é necessário ser um especialista em computação para aplicá-las em sala de aula ou em casa.

\footnotetext{
8 "Google for Education: Computational Thinking." https://edu.google.com/resources/programs/exploring_ computational-thinking/. Acessado em 21 fev. 2019.
} 
No livro "Computer Science Unplugged" (em português - Computação Desplugada), de Tim Bell, Lan H. Witten e Mike Fellows, são apresentadas várias atividades já pré-elaboradas que abrangem conceitos fundamentais da Ciência da Computação, sempre os relacionando com outras áreas do conhecimento, como a matemática.

Uma das atividades é a atividade "Contando os Pontos", onde se trabalha a conversão de números da base decimal para números binários e se discute a faixa de representação dos números no sistema binário. Essa atividade é indicada para pessoas com sete anos de idade ou mais.

Para aplicação da atividade "Contando os Pontos" no modo clássico proposto no livro, deve ser entregue um conjunto de cinco cartões para cada aluno. Os cartões devem conter um, dois, quatro, oito e dezesseis pontos, organizados na ordem decrescente, e de forma horizontal, conforme destacado na Figura 1. A atividade consiste em relacionar os cartões virados para baixo com o número zero, e os que estiverem para cima com o número um. Para formar os valores binários desejados, basta deixar virados para cima os cartões cujos valores somados resultem no valor decimal desejado, como se pode ver nos exemplos ilustrados pela Figura 1.

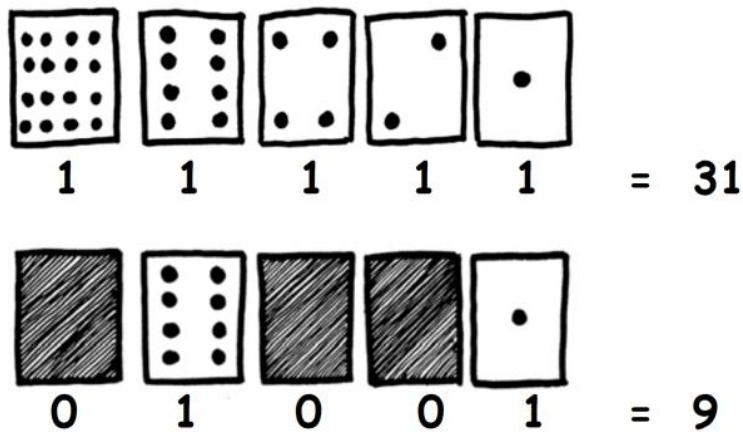

Figura 1. Contando os Pontos - Números Binários. Fonte: Imagem Adaptada do Livro de Bell et al, 2011, p. 4.

\subsection{Avaliação da Experiência do Usuário}

Atualmente, os instrumentos de avaliação da experiência do usuário vão de escalas simples de classificação de caneta e papel até equipamentos de alta tecnologia.

Os instrumentos podem ser separados em dois modos, protocolos verbais (métodos verbais) ou pictogramas (métodos não verbais) que são usados pelo usuário para classificar suas emoções. Os métodos mais utilizados para coleta subjetiva de sentimentos verbalmente são: entrevistas, inquéritos e método de amostragem de experiência. Já alguns dos métodos mais comuns para coleta de autorrelato usando pictogramas para avaliação não verbal de emoções são: Self Assessment Manikin (SAM) desenvolvido por Bradley e Lang (1994) e Emocards desenvolvido por Desmet et al. (2001).

Dentre os métodos supracitados, foi escolhido para este trabalho o método verbal de entrevista, utilizando-se da categoria das entrevistas semiestruturadas com perguntas baseadas na observação realizada durante a utilização do aplicativo em sala de aula.

Foi selecionado também o método não verbal SAM. Este método foi escolhido devido a sua facilidade de aplicação e análise, além de utilizar uma escala gráfica para medir a emoção do usuário a partir de sua satisfação, motivação e o sentimento de controle ao interagir com determinado recurso.

A satisfação é avaliada em uma escala de -4 a 4 , sendo zero neutralidade. A motivação e o sentimento de controle são avaliados em uma escala de 1 a 9. Conforme destacado por Silva et al. (2016), para obter o valor total representando o estado emocional do método SAM, aplica-se a fórmula:

$$
\text { (motivação + sentimento de controle) } * \text { satisfação (1) }
$$


Observando essa fórmula, pode-se ver que a satisfação, que pode assumir valor 0 , pode gerar um resultado de estado emocional também com valor 0. Conforme destacam Silva et al. (2016), para análise do estado emocional considera-se 72 pontos como pontuação máxima e -8 a pontuação mínima (baixa motivação, baixo sentimento de controle e insatisfação máxima).

\subsection{Prática Educativa com o Apoio de Tecnologias}

Conforme destacado por Tajra (2012), estamos vivendo um período revolucionário e cheio de mudanças e a educação necessita estar atenta ao mundo e não se marginalizar, tornando-se obsoleta e sem flexibilidade. Nesse sentido, a autora atenta para a necessidade de o professor possuir uma mente aberta para refletir criticamente sobre sua prática no processo de ensinoaprendizagem. Ela também ressalta que a escola precisa estar inserida no contexto tecnológico, mas que ao se utilizar na educação os recursos tecnológicos, sempre se questione o objetivo que se quer atingir, avaliando sempre as virtudes e limitações dos recursos. É nesse sentido que o atual trabalho se insere ao avaliar um recurso educacional digital para apoiar a educação em computação. Recursos educacionais digitais são muitas vezes chamados de objetos de aprendizagem (OA), como destacado por Rebouças et al. (2021), que refletem também sobre a importância do propósito pedagógico ao adotar um OA em sala de aula e sobre a forma como é feita essa integração e que é um fator determinante para que o objetivo pedagógico seja atingido.

\section{Trabalhos Relacionados}

Este trabalho apresenta forte relação com o trabalho de Oliveira et al. (2019) e que apresenta o aplicativo "Computação Plugada", destacando o seu propósito de simplificar e disseminar a aplicação de atividades de computação desplugada. No entanto, no trabalho apresentado não é feita nenhuma avaliação nesse sentido, que é exatamente o que o presente artigo apresenta.

Um outro trabalho relacionado é o de Pessoa et al. (2017), que apresenta o T-mind, um aplicativo "gamificado" inspirado no Duolingo 9 com o intuito de estimular o desenvolvimento das habilidades do pensamento computacional sem necessidade de conhecimento em programação. Esse artigo é relacionado, pois também destaca os bons resultados de um aplicativo mobile para apoiar o desenvolvimento do pensamento computacional.

No trabalho de Pinho et al. (2016) é apresentado um aplicativo com versões para desktop e plataformas mobile (Windows Phone, Android e iOS), baseado em uma adaptação da atividade "Batalha Naval - Algoritmos de Busca" da computação desplugada. Essa adaptação teve o nome de "Caça ao Tesouro". Também é descrita uma comparação entre os resultados da aplicação com o aplicativo e aplicação através do método clássico desplugado. Os resultados relativos ao desempenho médio das três turmas submetidas à metodologia clássica não diferiram significativamente do desempenho médio da turma submetida ao método com o uso do aplicativo segundo o teste $\mathrm{t}, \operatorname{com} \alpha=0,05$. Sendo assim, não foi possível concluir sobre sua superioridade. No entanto, o artigo destacou que colaboradores do projeto e o próprio professor da escola, que acompanharam ambas as aplicações, observaram que os alunos se mostraram bem mais motivados na execução da atividade plugada. No presente trabalho focou-se apenas na avaliação da aceitação do aplicativo pelos estudantes e a comparação entre atividades desplugadas ou através do aplicativo foi realizada apenas por docentes, como detalhado nas seções seguintes.

Diversos outros trabalhos descrevem jogos digitais voltados ao ensino de conceitos da computação, como é o caso do trabalho de Netto et al. (2017), que desenvolveu um aplicativo Android denominado de "Game Logic" com o intuito de auxiliar na aprendizagem de lógica de programação. Outro trabalho nessa linha é o de Silva et al. (2018), que relata o jogo "As Aventuras

9 "Duolingo." https://pt.duolingo.com/. Acessado em 23 mar. 2019. 
de Ada e Turing", que busca favorecer o desenvolvimento das habilidades do PC em estudantes do Ensino Fundamental I. Porém, em nenhum destes trabalhos são usadas atividades da computação desplugada.

No trabalho de Gibson e Bell (2013) são identificados jogos para o ensino de tópicos em Ciência da Computação, como programação e números binários e são destacadas estratégias desplugadas, mobile, baseadas em desktop, e baseadas em navegadores. Os autores destacam que a atividade desplugada de números binários da forma como é apresentada não é um jogo conforme definem no artigo já que alguns desafios são oferecidos para os estudantes. Porém, dizem que ela poderia ser "gamificada" gerando um número arbitrário de conjuntos de números a serem convertidos, aumentando o número de bits a serem convertidos à medida que os estudantes vão ficando mais proficientes. De certa forma, ideias como esta foram exploradas no aplicativo "Computação Plugada" de Oliveira et al. (2019) e no presente trabalho a ideia foi avaliar na prática esse uso por estudantes e analisar a impressão de docentes que já trabalharam com atividades de computação desplugada, algo não encontrado na literatura até onde se pesquisou.

Também são relacionados ao presente artigo trabalhos como o de Sandoval-Bringas et al. (2018) em universidade no México e que analisa a aprendizagem móvel (M-Learning). Os autores apontam aspectos como o rápido feedback fornecido e a forte aceitação dos estudantes do ensino superior por esse tipo de recurso de apoio ao ensino. $\mathrm{O}$ artigo também destaca que atualmente muitos estudantes contam com dispositivos móveis. Um outro trabalho, e que foi realizado no Peru, por Gutierrez-Aguilar e Salas-Valdivia (2019) também destaca a importância de se utilizar dispositivos móveis como ferramenta para melhorar o processo educativo e não só um meio de comunicação e entretenimento. Embora este estudo tenha se focado no uso da rede social Facebook, ele tem relação com o presente trabalho também por destacar aspectos relacionados à aprendizagem colaborativa já que no presente trabalho, conforme destacado a seguir, viu-se que foi bem positiva a colaboração entre os estudantes durante o uso do aplicativo "Computação Plugada" em sala de aula, sendo, portanto, importante observar a forma como se explora um aplicativo em sala de aula. Nas conclusões de Gutierrez-Aguilar e Salas-Valdivia (2019) os autores destacam a importância de ações que proporcionem a colaboração entre pares e onde o professor é um mediador da aprendizagem.

\section{Metodologia}

Como se busca investigar o uso das atividades de computação desplugada por meio do aplicativo "Computação Plugada", considerou-se que um estudo em um contexto real de ensino poderia trazer resultados valiosos. Além disso, buscou-se investigar a opinião de professores e outros possíveis usuários do aplicativo que fossem estudantes e que poderiam utilizá-lo e avaliá-lo mesmo sem a observação de pesquisadores. Conforme explicitado na introdução, este trabalho buscou investigar como se dá a aceitação da utilização de um aplicativo Android com exercícios da computação desplugada por professores de computação e por alunos.

A pesquisa aqui relatada envolveu um estudo observacional com fins de avaliação de uma ferramenta e também envolveu levantamento de dados por meio de questionários online. No primeiro momento da pesquisa foi utilizado um questionário (Apêndice $\mathrm{A}$ ) online elaborado no Google Forms ${ }^{10}$ com o objetivo de coletar a opinião de professores da área de computação quanto à utilização do aplicativo Computação Plugada como ferramenta instrucional para auxiliar no ensino. Este questionário teve suas respostas restritas a profissionais que possuíam experiência na aplicação de atividades desplugadas, para que os mesmos tivessem uma noção mínima para

10 "Google Forms: Free Online Surveys for ...." https://www.google.com/forms/about/. Acessado em 23 jan. 2021. 
comparação entre os métodos de aplicação da atividade trabalhada no aplicativo. 8 professores de computação responderam ao questionário.

Para investigar a aceitação por parte de usuários alunos foi aplicado um questionário (Apêndice B) com perguntas sobre usabilidade, percepção de aprendizagem, aceitação do uso do aplicativo, além do questionário SAM desenvolvido por Bradley e Lang (1994), com pictogramas para avaliar satisfação, motivação e controle utilizando no questionário online uma escala de 1 a 9. É importante destacar, porém, que embora no questionário online se tenha utilizado uma escala de 1 a 9 para a satisfação, estas respostas foram convertidas para uma escala de -4 a 4 para o cálculo do estado emocional. Esse questionário foi enviado através de e-mail para alunos do primeiro período dos cursos de Licenciatura em Ciência da Computação e Bacharelado em Sistemas de Informação da UFPB - Campus IV, além de alguns convites enviados a contatos pessoais, obtendo-se no total 21 respostas.

Para explorar o contexto de aplicação em sala de aula, foram selecionadas 3 turmas do primeiro ano do ensino médio e do curso integrado de informática da ECIT Presidente João Goulart em João Pessoa. Os alunos, guiados pela professora, foram submetidos à utilização do aplicativo, agrupados em duplas ou em trios quando necessário. Foram utilizados 10 tablets cedidos pela Universidade Federal da Paraíba nos modelos Samsung Galaxy Tab 3 e Samsung Galaxy Tab 4. Após a conclusão de todos os níveis do aplicativo, os 68 alunos responderam individualmente o mesmo questionário de avaliação do aplicativo preparado para usuários alunos que utilizaram de forma independente o aplicativo e que está apresentado no Apêndice B.

Enquanto técnica de pesquisa, julgou-se mais adequada a observação espontânea durante a aplicação das atividades. Na observação espontânea, o pesquisador, permanecendo alheio à comunidade, grupo ou situação que pretende estudar, observa os fatos que aí ocorrem. É adequada, pois favorece a aproximação do pesquisador com o fenômeno pesquisado (Gil, 2017). Para essa observação, foi criado um protocolo de observação detalhado no Apêndice C, que foi utilizado durante a aplicação das atividades com os alunos em sala de aula. Por meio desse protocolo, buscou-se analisar a ocorrência de eventos que indicassem interesse, desinteresse e colaboração entre os estudantes durante o uso do aplicativo em sala. Buscou-se também observar o progresso desses estudantes nos níveis do aplicativo ao longo de cada aula, identificando o tempo necessário para que os grupos concluíssem tais níveis.

Ao fim de todas as aplicações, foi realizada uma pequena entrevista semiestruturada com a professora responsável pela aplicação das atividades com o aplicativo na sala de aula, cujo roteiro está apresentado no Apêndice D.

\section{O Aplicativo Computação Plugada}

Conforme descrito no trabalho de Oliveira et al. (2019), o "Computação Plugada" é um aplicativo desenvolvido para dispositivos que possuem o sistema operacional Android 4.0 ICE_CREAM_SANDWICH (API Level: 15) ou posterior.

O Aplicativo pode ser baixado no endereço https://sites.google.com/view/computacaoplugada/download e sua primeira versão, descrita no artigo, e avaliada neste trabalho, foi implementada no ambiente integrado de desenvolvimento Android Studio, utilizando-se o Android SDK e a linguagem de programação JAVA. A persistência dos dados é feita utilizando o banco de dados nativo do próprio Android, o SQLite.

Para essa primeira versão do aplicativo "Computação Plugada" foi escolhida a atividade "Contando os Pontos-Números Binários", da primeira parte do livro de Bell et al. (2011), denominada "Dados: A Matéria-prima—Representando a informação". Essa atividade discute a 
forma como os computadores armazenam as informações em dados e como se comunicam entre si, através de códigos binários (0 e 1).

Nas Figuras 2, 3 e 4 apresentadas a seguir podemos observar algumas telas do aplicativo. Nas telas iniciais (Figura 2), ao iniciar, o usuário irá ver inicialmente a tela de Splash Screen por três segundos. Depois será redirecionado para a tela principal onde terá a opção de pausar a música de fundo através do botão de som no canto superior direito da tela. Poderá também acessar as informações do aplicativo pressionando o botão SOBRE ou seguir para telas de seleção de níveis (Figura 3), pressionando o botão INICIAR.

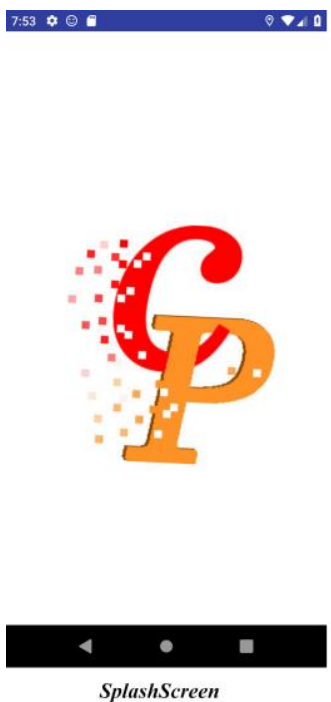

SplashScreen

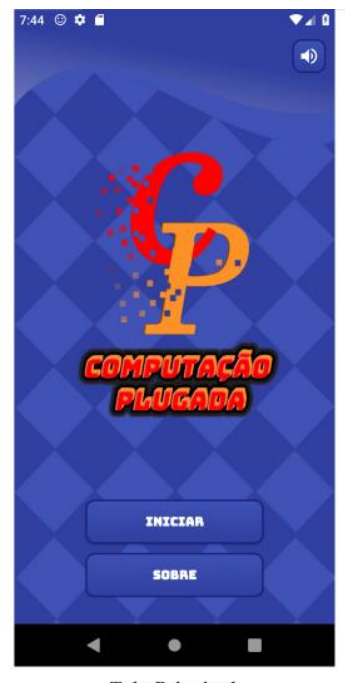

Tela Principal

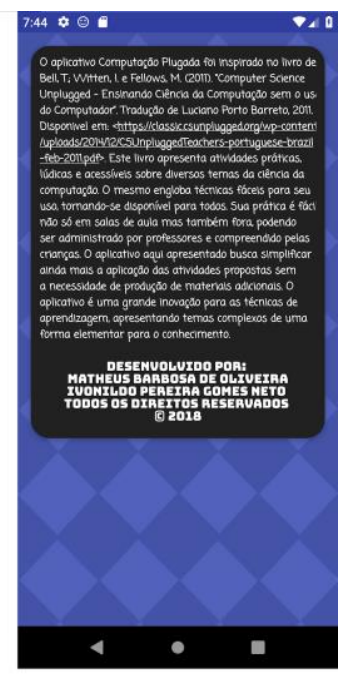

Tela Sobre

Figura 2. Telas iniciais do aplicativo. Fonte: Oliveira et. al (2019).

Na Figura 3 é apresentada a tela de atividades que é exibida logo após o usuário pressionar o botão iniciar e que inclui apenas a atividade "Contando os Pontos-Números Binários".

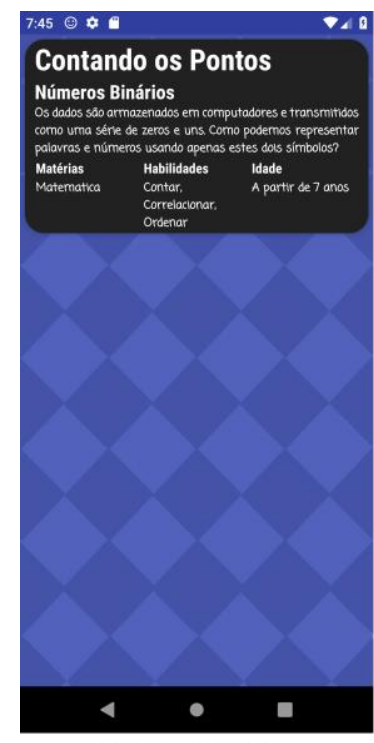

Tela de Atividades

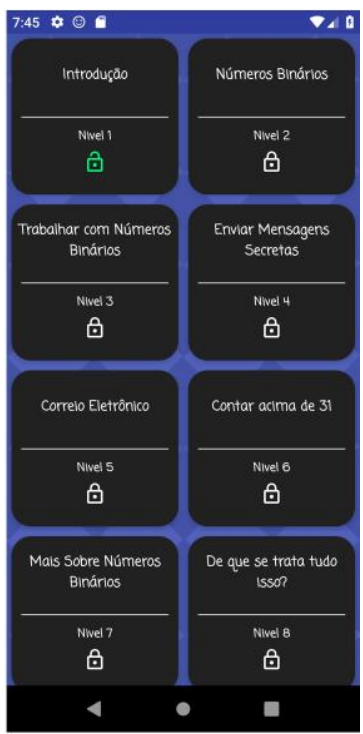

Tela de Exercicios

Figura 3. Telas de seleção de níveis. Fonte: Oliveira et. al (2019).

Pressionando o cartão da atividade, o usuário será direcionado para a tela de exercícios, onde serão exibidos os 8 níveis de exercícios implementados. Inicialmente, o usuário terá acesso apenas ao primeiro nível, exibido com um cadeado aberto na cor verde, enquanto os demais níveis são exibidos com cadeados fechados. A cada nível finalizado, o próximo será liberado para o usuário até que finalize todos os exercícios disponíveis. 
A Figura 4 ilustra a tela de exercício do nível 1. O usuário deve responder todas as questões e pressionar o botão "FINALIZAR". Caso as respostas estejam corretas, o nível será completado e o usuário poderá escolher entre voltar para a lista de níveis, refazer atividade ou começar uma nova fase. Caso contrário, o usuário receberá um feedback indicando que a resposta à questão está incorreta.

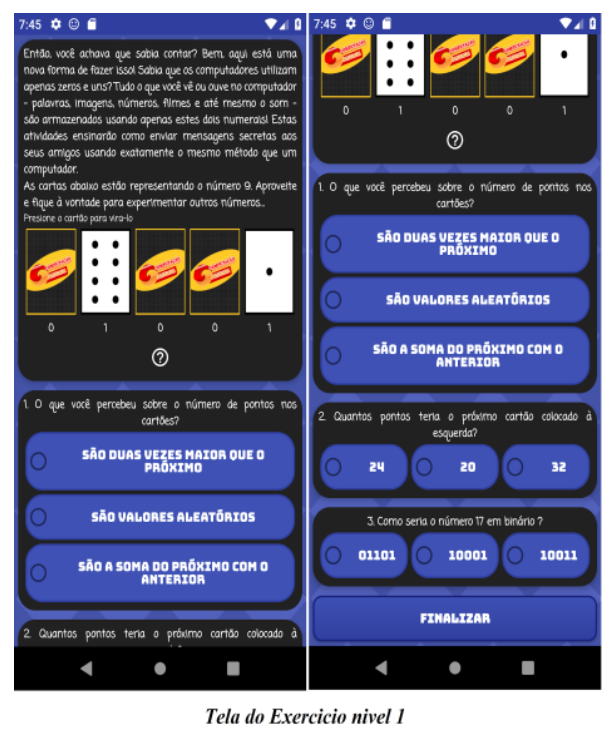

Figura 4. Exemplo de exercício (Nível 1 - Introdução). Fonte: Oliveira et. al (2019).

A cada nível são apresentadas diferentes questões com base no livro, mas com feedback automático. Uma descrição de cada nível pode ser encontrada no Quadro 1.

\begin{tabular}{|c|c|}
\hline Nível & Descrição \\
\hline Nível 1 - Introdução & $\begin{array}{l}\text { Usuário pode manipular os cartões e deve responder } 3 \text { questões de múltipla } \\
\text { escolha. }\end{array}$ \\
\hline Nível 2 - Números Binários & $\begin{array}{l}\text { É possível manipular os cartões. } \\
\text { Possui uma questão aberta e duas de múltipla escolha. }\end{array}$ \\
\hline $\begin{array}{l}\text { Nível } 3 \text { - Trabalhar com } \\
\text { Números Binários }\end{array}$ & $\begin{array}{c}\text { São exibidas dez imagens com legendas em que o usuário deve traduzir para } \\
\text { binário e converter em decimal. }\end{array}$ \\
\hline $\begin{array}{l}\text { Nível } 4 \text { - Enviar Mensagens } \\
\text { Secretas }\end{array}$ & $\begin{array}{l}\text { É apresentado um enredo em que um personagem chamado Tom tenta enviar } \\
\text { uma mensagem utilizando um código binário. } \\
\text { O usuário deve converter todos os números para decifrar a mensagem enviada. }\end{array}$ \\
\hline Nível 5 - Correio Eletrônico & $\begin{array}{c}\text { O usuário envia uma mensagem que é rapidamente respondida em binário. } \\
\text { O usuário deve converter corretamente a mensagem de resposta para finalizar } \\
\text { o exercício. }\end{array}$ \\
\hline Níveis 6 - Contar acima de 31 & $\begin{array}{c}\text { Três questões de múltipla escolha com um nível mais elevado de } \\
\text { complexidade, onde o usuário é desafiado a contar além do máximo possível } \\
\text { com os cartões. }\end{array}$ \\
\hline $\begin{array}{l}\text { Nível } 7 \text { - Mais Sobre Números } \\
\text { Binários }\end{array}$ & $\begin{array}{l}\text { Mais três questões de múltipla escolha abordando outros conceitos da } \\
\text { matemática e da relação binário-decimal. }\end{array}$ \\
\hline $\begin{array}{c}\text { Nível } 8 \text { - De que se trata tudo } \\
\text { isso }\end{array}$ & $\begin{array}{l}\text { Não possui nenhum exercício, apresenta apenas uma explicação mais } \\
\text { detalhada sobre números binários e sua importância. }\end{array}$ \\
\hline
\end{tabular}




\section{Resultados}

Nessa seção são apresentados os principais resultados dos estudos realizados por meio de levantamento de dados com questionários online e com o estudo observacional.

\subsection{Avaliação Realizada por Professores através do Questionário Online}

Foi realizada uma consulta a professores da área de computação através de um questionário que buscava identificar a familiaridade do professor com a computação desplugada e sua opinião sobre a possível utilização do aplicativo em suas aulas. Foram obtidas 8 respostas de professores, sendo 6 homens (identificados por P1, P2, P3, P5, P7 e P8) e 2 mulheres (identificadas por P4 e P6). Destes professores, 6 eram formados em Licenciatura em computação (P2, P3, P4, P5, P7 e P9), 1 era licenciando em computação (P1) e 1 era bacharel em Engenharia da Computação (P6). 4 dos professores tinham mestrado em computação (P4, P5, P6 e P7). Dentre as disciplinas ensinadas por estes professores, foram citadas as seguintes: Arquitetura de computadores (P1, P2), linguagem de programação ou programação ou algoritmos (P2, P3, P4, P5, P6, P7 e P8), eletrônica (P1, P2), sistemas operacionais (P2, P3, P5, P6, P8), informática básica (P1, P7, P8), banco de dados, dentre outras. Dentre os participantes, 37,5\% (3 deles: P4, P5 e P7) já leciona há 5 anos ou menos e mais de 2 anos e 62,5\% (5 deles: P1, P2, P3, P6 e P8) lecionam há dois anos ou menos.

Cinco desses professores (P2, P3, P4, P5 e P7) já haviam aplicado com seus alunos a atividade "Contando os Pontos - Números Binários" pelo modo tradicional, impresso. Outro dado importante é que $75 \%$ dos professores (6 dentre os 8 ) responderam que concordam com grau 4 ou 5 com a seguinte afirmação: "Assumindo que há dispositivos disponíveis para os alunos, acredito que aplicar as atividades com o aplicativo Computação Plugada parece tornar mais simples a aplicação do que da forma convencional." A escala de Likert utilizada na pergunta vai de 1 (Discordo Totalmente) a 5 (Concordo Totalmente) e as respostas obtidas estão ilustradas pela Figura 5.

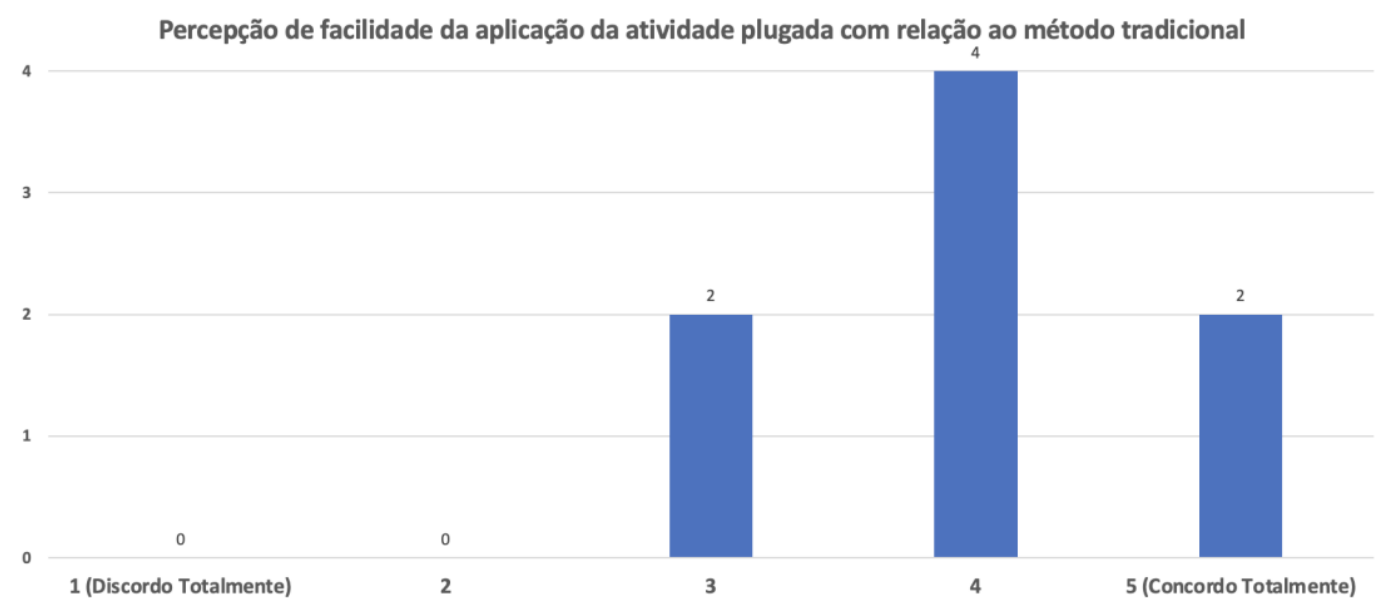

Figura 5. Nível de concordância dos professores com a afirmação "Assumindo que há dispositivos disponíveis para os alunos, acredito que aplicar as atividades com o aplicativo Computação Plugada parece tornar mais simples a aplicação do que da forma convencional."

Fonte: Os Autores.

Analisando as respostas, viu-se que 2 professores (P3, P4) escolheram o nível 5, 4 professores (P1, P5, P6 e P7) escolheram o Nível 4 e 2 professores (P2 e P8) escolheram o nível 3. Sendo assim, foi possível identificar que dentre os seis professores que selecionaram o nível igual ou superior a 4 para a afirmação apresentada na Figura 5, 4 já possuíam experiência docente com a atividade "Contando os pontos - números binários". Isso dá indícios de que professores com experiência no método tradicional tendem a classificar o app como um facilitador da aplicação das atividades desplugadas. 
Foram também analisadas as respostas dadas à questão 10, que se refere ao quão fácil foi para o participante usar o aplicativo. Dentre as respostas, que estão ilustradas na Figura 6, viu-se que 3 dos respondentes $(37,5 \%)$ se mostraram neutros, 4 escolheram o Nível 4 e apenas um o Nível 5 , o que mostra que podem ser feitas melhorias para tornar o uso do aplicativo mais fácil. Esse aspecto foi identificado também nos feedbacks oferecidos por meio das respostas à penúltima questão do formulário, onde foram sugeridas melhorias na interface.

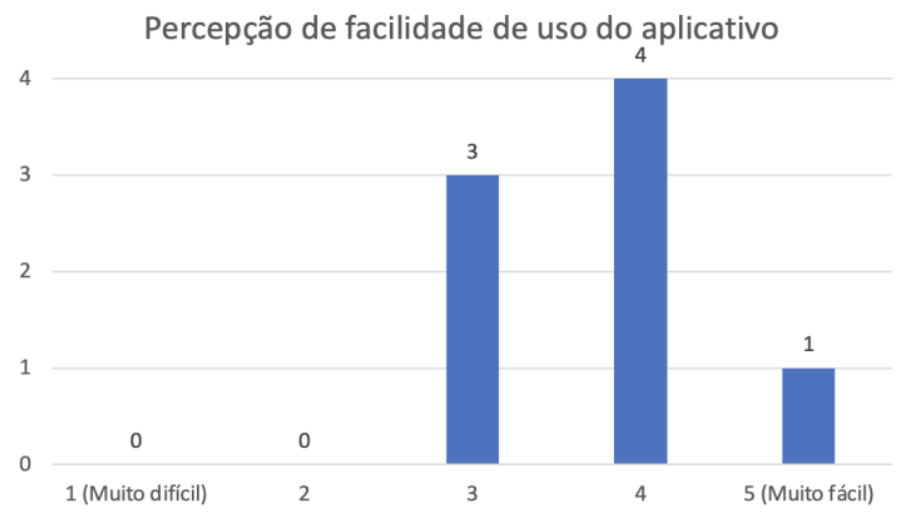

Figura 6. Respostas dos professores relativa ao quão fácil de usar consideraram o aplicativo em uma escala de 1 (Muito difícil) a 5 (Muito fácil). Fonte: Os Autores.

Ao serem questionados sobre a chance de indicar o aplicativo para outras pessoas utilizando uma escala de 0 (Nenhuma) a 10 (Muito alta), viu-se que todos indicaram níveis superiores a 5, conforme ilustrado pela Figura 7, tendo a maioria (7) indicado uma chance maior ou igual a 8, o que dá indícios de que houve uma boa aceitação por parte dos professores.

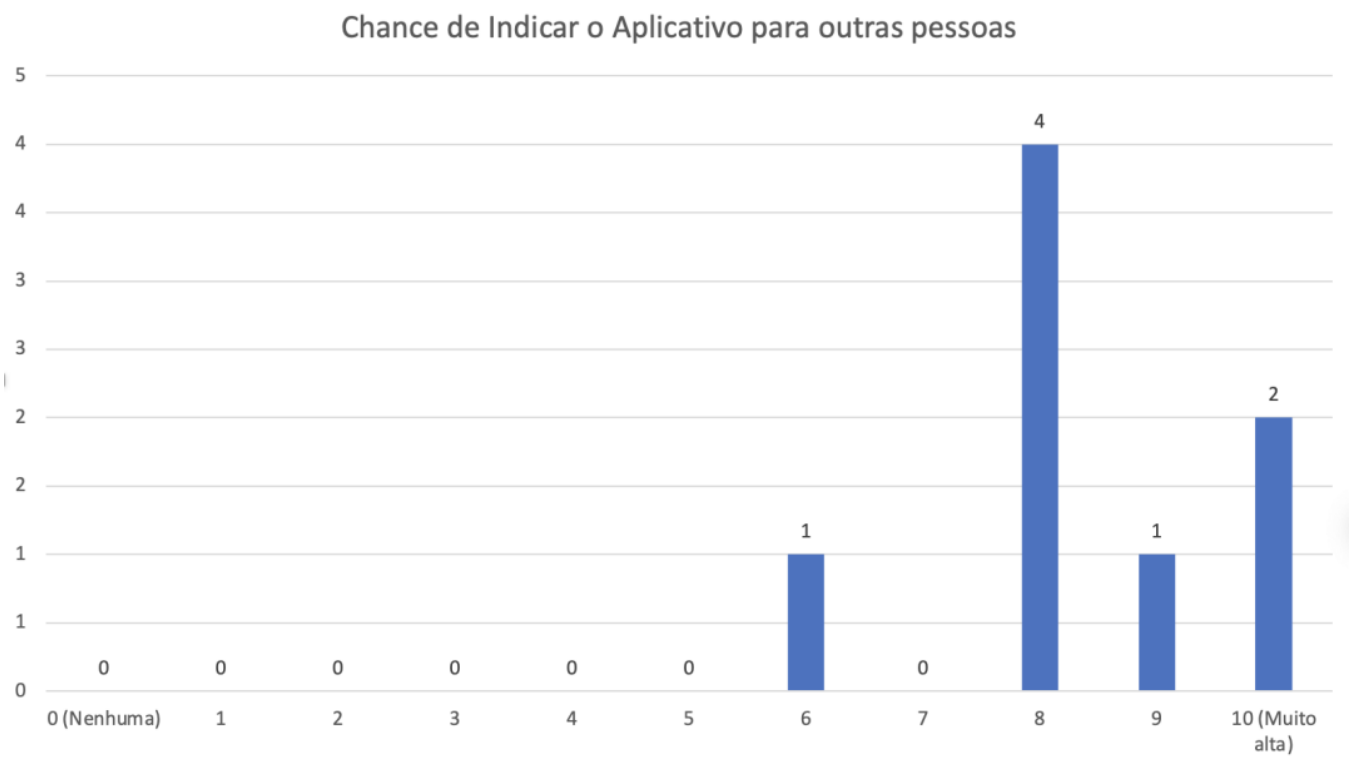

Figura 7. Respostas dos professores sobre a chance de indicar o App Computação Plugada para outras pessoas utilizando escala de 1 (Nenhuma) a 5 (Muito alta).

Fonte: Os Autores.

\subsection{Avaliação Realizada por Usuários Alunos Através do Questionário Online e que não Fizeram Parte da Observação}

No questionário aplicado a distância com possíveis usuários alunos quanto ao uso do aplicativo, foram obtidas 21 respostas sendo 10 de homens e 11 de mulheres, com idades entre 10 e 25 anos. Dentre os estudantes que responderam, $57.1 \%$ são estudantes do ensino superior na área de computação, 19,05\% são estudantes de graduação de outras áreas, 19,05\% são alunos de ensino 
médio ou técnico e 4,8\% (1 estudante) do ensino fundamental. Além disso, viu-se que $80.95 \%$ dos colaboradores afirmaram que completaram ao menos metade dos níveis do aplicativo antes de realizar a avaliação.

Tabela 1. Resultados do Questionário de Avaliação SAM

\begin{tabular}{|c|c|c|c|c|c|c|c|c|c|c|c|c|c|c|c|c|c|c|c|c|c|}
\hline SAM & \multicolumn{110}{|c|}{ Usuários } \\
\hline & $\mathbf{1}$ & $\mathbf{2}$ & $\mathbf{3}$ & $\mathbf{4}$ & $\mathbf{5}$ & $\mathbf{6}$ & $\mathbf{7}$ & $\mathbf{8}$ & $\mathbf{9}$ & $\mathbf{1 0}$ & $\mathbf{1 1}$ & $\mathbf{1 2}$ & $\mathbf{1 3}$ & $\mathbf{1 4}$ & $\mathbf{1 5}$ & $\mathbf{1 6}$ & $\mathbf{1 7}$ & $\mathbf{1 8}$ & $\mathbf{1 9}$ & $\mathbf{2 0}$ & $\mathbf{2 1}$ \\
\hline Satisfação & 3 & 3 & 3 & 0 & -1 & 4 & 3 & 2 & 4 & 3 & 3 & 2 & 3 & 3 & 4 & 4 & 4 & 4 & 3 & 4 & 4 \\
\hline Motivação & 8 & 7 & 9 & 4 & 6 & 9 & 8 & 6 & 7 & 9 & 8 & 8 & 7 & 7 & 7 & 1 & 9 & 8 & 8 & 9 & 8 \\
\hline Controle & 9 & 9 & 7 & 6 & 5 & 9 & 8 & 8 & 8 & 6 & 9 & 9 & 5 & 8 & 9 & 5 & 9 & 9 & 7 & 6 & 7 \\
\hline Total & 51 & 48 & 48 & 0 & -11 & 72 & 48 & 28 & 60 & 45 & 51 & 34 & 36 & 45 & 64 & 24 & 72 & 68 & 45 & 60 & 60 \\
\hline
\end{tabular}

A Tabela 1 mostra os resultados obtidos no questionário SAM, inclusive o total considerando a fórmula (1) apresentada na Seção 2.3 referentes ao estado emocional. Podemos observar que para 19 dentre os 21 colaboradores (C), a satisfação, que foi analisada na escala de -4 a 4 , foi considerada positiva (maior que zero). Dentre esses, destacam-se os colaboradores C6, C9, C15, C16, C17, C18, C20 e C21 que avaliaram o quesito com nota máxima. Apenas para um dos colaboradores a satisfação foi negativa e tivemos uma resposta com valor " 0 ", considerado como uma neutralidade. A média obtida para esse item foi de 2,95, a mediana foi de 3 e o desvio padrão da amostra foi de 1,32 .

A motivação obteve bons índices, já que mais da metade dos colaboradores assinalaram uma resposta maior do que 7 em uma escala variando de 1 a 9, enquanto apenas dois marcaram um número menor do que 5. A média obtida para a motivação foi de 7,29 , a mediana foi de 8 e o desvio padrão da amostra foi de 1,90. Já com relação ao sentimento de controle, foi obtida uma média de 7,52 na escala de 1 a 9, com mediana de 8 e desvio padrão da amostra de 1,50. Podemos perceber também que 8 dentre os 21 participantes assinalaram o nível máximo (9) nesse quesito.

Após a realização dos cálculos e obtenção do valor total do estado emocional, observamos uma média de 45,14, com uma mediana de 48 e um desvio padrão da amostra de 21,46 em uma escala que varia de -8 (satisfação -4 , motivação 1 e controle 1) a 72, conforme descrito por Silva et al. (2016). Viu-se que um colaborador foi considerado como nulo, já que a emoção obtida por seus dados foi neutra. Outro colaborador reportou índice de avaliação negativo, porém indicou altos índices de motivação e controle, o que levou, apesar disso, a uma pontuação menor à considerada mínima (-8) segundo Silva et al. (2016). Os demais demonstraram resultados acima da média (32), porém o pico de satisfação, motivação e controle (valor total de 72) foi obtido em apenas dois colaboradores (C6 e C17).

\subsection{Avaliação pelos Alunos que fizeram parte do Estudo por Observação}

O aplicativo foi usado em três turmas do primeiro ano do ensino médio e técnico integrado em informática em suas respectivas aulas. Os alunos tinham entre 14 e 32 anos, sendo a média de idade de 15,92 anos, mediana de 16 e desvio padrão da amostra de 2,15. Destes, 59,5\% eram homens e 39,3\% mulheres. Um dos alunos não quis se identificar quanto ao seu gênero. Guiados pela professora, os alunos foram separados em 30 duplas ou trios e instigados a completar todos os níveis contidos na versão atual do aplicativo, e ao final, preencheram o formulário de avaliação.

Dentre os aspectos observados, um deles foi se os alunos estavam conseguindo concluir os diferentes níveis do jogo. A Tabela 2 mostra o número de equipes (duplas ou trios) que estavam em cada nível do jogo após os 30 minutos de início da atividade e a cada 10 minutos. Na última linha se mostra a quantidade de equipes que já concluíram em cada momento. 
Tabela 2. Número de equipes (duplas ou trios) que estavam em cada nível por momento observado.

\begin{tabular}{|c|c|c|c|c|c|c|}
\hline & $30 \mathrm{~min}$ & $40 \mathrm{~min}$ & 50 min & $60 \mathrm{~min}$ & $70 \mathrm{~min}$ & 80 min \\
\hline Nível 1 & 0 & 0 & 0 & 0 & 0 & 0 \\
\hline Nível 2 & 0 & 0 & 0 & 0 & 0 & 0 \\
\hline Nível 3 & 10 & 0 & 0 & 0 & 0 & 0 \\
\hline Nível 4 & 9 & 7 & 3 & 0 & 0 & 0 \\
\hline Nível 5 & 5 & 5 & 3 & 0 & 0 & 0 \\
\hline Nível 6 & 2 & 8 & 4 & 5 & 0 & 0 \\
\hline Nível 7 & 1 & 3 & 3 & 3 & 0 & 0 \\
\hline Nível 8 & 1 & 2 & 3 & 1 & 1 & 0 \\
\hline Terminou & 2 & 4 & 14 & 21 & 29 & 30 \\
\hline
\end{tabular}

Podemos observar na Tabela 2 que as primeiras equipes ao concluir todas as atividades, incluindo a resposta individual ao questionário de avaliação, o fizeram nos 30 primeiros minutos da aplicação. Podemos ver também que o intervalo 40-50, foi o que obteve o maior número de finalizações. No minuto 40 apenas quatro das equipes haviam finalizado todos os níveis, já na verificação seguinte, 10 minutos depois, quatorze equipes conseguiram o êxito na conclusão dos níveis, somando 10 equipes no total a concluírem no intervalo. O tempo máximo usado por uma equipe para concluir todos os níveis e preencher o formulário de avaliação do aplicativo foi de 80 minutos.

Outro detalhe importante é observar que o nível 3 foi o que obteve maior retenção de tempo dos alunos. Na primeira observação que ocorreu aos 30 minutos, 10 das 30 equipes ainda não haviam completado este nível. Em nenhuma outra atividade foi identificado um número tão alto de equipes.

Além de observar os níveis que iam sendo concluídos pelos alunos, observou-se também o seu interesse e colaboração durante a realização da atividade com o aplicativo, por meio dos aspectos listados no protocolo de observação do Apêndice C. Durante as atividades em sala de aula, foi possível observar de maneira clara um grande interesse por parte dos alunos. Os aspectos de desinteresse considerados no protocolo de observação, como conversas paralelas ou uso do dispositivo para outras finalidades, não foram observados nas 3 turmas. Além disso, havia forte interação entre os membros de cada equipe buscando a resolução dos exercícios. Viu-se também que pediam ajuda da professora constantemente ao terem dúvidas e prestavam atenção na explicação da mesma. Outro fato observado em algumas equipes foi a comemoração ao finalizar algum nível.

De maneira geral, todas as equipes conseguiram concluir os níveis em um tempo aceitável, já que apenas 9 das 30 equipes passaram de uma hora para realizar completamente a atividade proposta e apenas uma equipe ultrapassou a marca dos 70 minutos. Não foi observada em nenhum momento a utilização dos tablets para outros fins.

Após o fim das atividades, os alunos eram submetidos individualmente ao questionário de avaliação do aplicativo. Apenas um aluno não concordou em participar da pesquisa, tendo sido obtidas 68 respostas.

Quanto à percepção da aprendizagem, foram obtidos resultados muito positivos, considerando que $72,1 \%$ dos alunos responderam que acreditam que o aplicativo contribuiu muito para o seu aprendizado sobre números binários (Nível 5 na escala de 1 a 5), conforme ilustrado pelo Figura 8. 
O quanto o aplicativo em si contribuiu para o seu aprendizado sobre números binários?

68 respostas

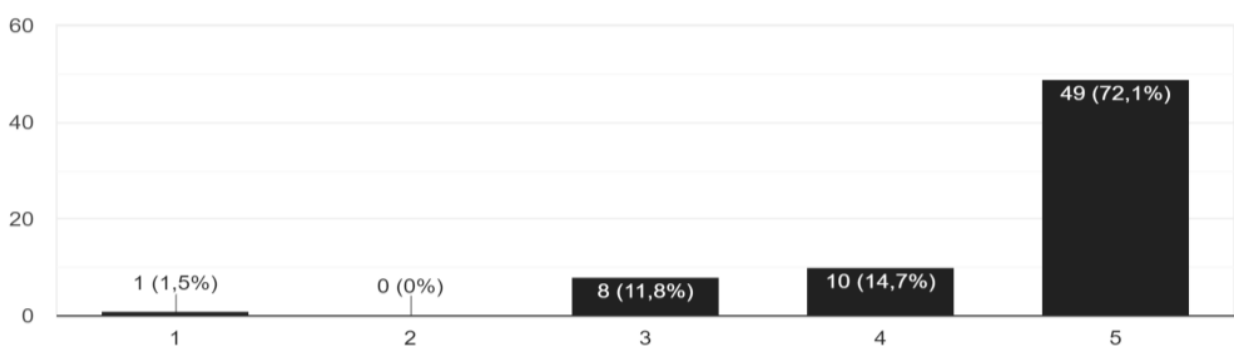

Figura 8. Percepção de aprendizagem dos alunos quanto ao conteúdo visto com o apoio do aplicativo do Nível 1 (Contribuiu pouco) ao Nível 5 (Contribuiu muito)

Fonte: Os Autores.

As justificativas dadas pelos alunos para a resposta ilustrada pelo gráfico da Figura 8 foram muitas. Alguns exemplos são as seguintes: "Ajudou a compreender o código binário e seus inúmeros desafios", "Porque eu não sabia nada sobre números binários e agora aprendi pelo menos um pouco", "Uma aula diferente das outras", "Modo fácil de ensino", etc. Os dois últimos exemplos dão indícios de que os alunos tiveram uma identificação com a utilização dos tablets com o aplicativo na sala de aula e que acreditam que essa abordagem melhora o seu aprendizado. Também foi relevante a observação do aluno sobre ter aprendido mesmo sem ter tido contato prévio com o conteúdo antes.

Já com relação à aparência do aplicativo, houve muitos feedbacks solicitando melhorias na interface e mudança nas cores. Alguns exemplos de sugestões de melhoria foram: "Um estudo de teoria das cores", "Ele pode melhorar na estética", "Diminuir os textos na tela", "Os desenhos das questões mais animadas". Isso reforça a necessidade de melhorias na interface de interação com o usuário considerando a versão do aplicativo que foi avaliada (primeira versão), sendo importante uma análise do público-alvo principal que o aplicativo deseja atingir. Foi possível observar também respostas solicitando a implementação de mais níveis e/ou mais atividades no aplicativo.

Foram reportados 9 problemas de desempenho no app, dentre eles travamentos e lentidão foram os mais frequentes.

Por fim, acredita-se que de maneira geral os estudantes se mostraram satisfeitos com o aplicativo, conforme ilustrado pela Figura 9, que mostra o resultado das respostas dos alunos com relação às chances de indicação do aplicativo para outras pessoas em uma escala de 0 a 10.

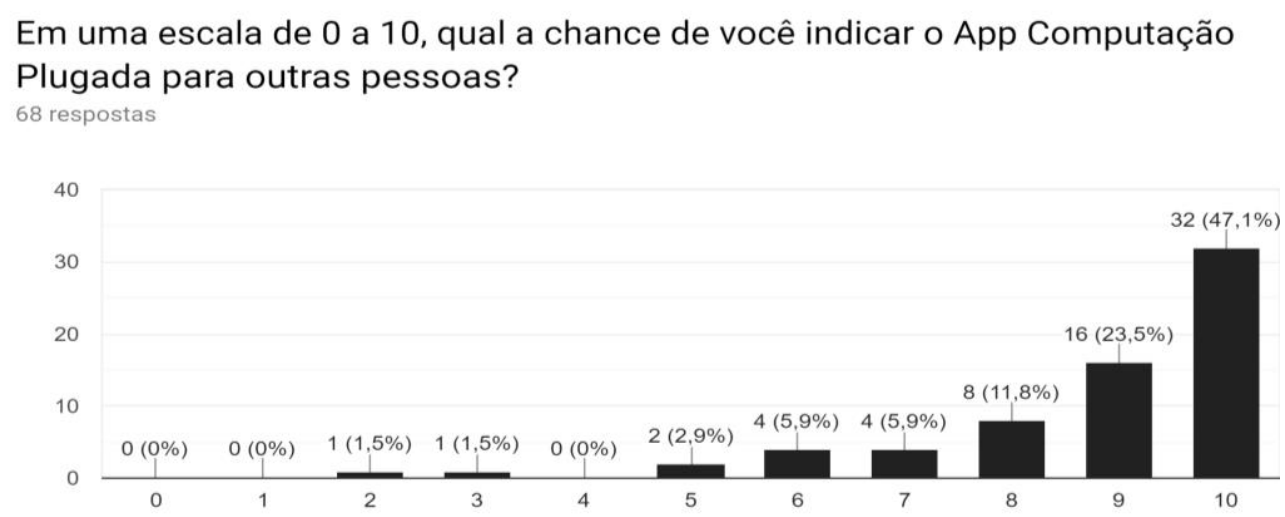

Figura 9. Possibilidade de indicação do aplicativo pelos alunos de 0 (Nenhuma) a Muito Alta (10).

Fonte: Os Autores. 
Com relação aos resultados da avaliação SAM, foi possível observar que $32,35 \%$ dos participantes (22 dos 68) forneceram nota máxima nos três quesitos. Para o outro grupo que preencheu o formulário, mas que não participou dessa observação, o percentual de avaliações máximas foi de $9,52 \%$. No entanto, ao comparar as duas amostras utilizando o Mann-WhitneyWilcoxon Test ao nível de significância de 0,05 , não é possível afirmar que há realmente diferença estatisticamente significante entre os valores obtidos para emoção $(\mathrm{W}=565,5 ; \mathrm{p}=0,1483)$, motivação ( $\mathrm{W}=561 ; \mathrm{p}=0,122)$, satisfação $(\mathrm{W}=617 ; \mathrm{p}=0,3092)$ e controle $(\mathrm{W}=633,5 ; \mathrm{p}=0,4136)$. $\mathrm{O}$ resultado completo com todos os participantes do grupo observado pode ser encontrado no Apêndice E. Também não foram encontradas diferenças significativas ao comparar a possibilidade de indicação do aplicativo com o grupo que não participou da observação, onde 90,5\% indicaram uma chance maior ou igual a 7 de indicar, enquanto neste grupo observado essa percentagem foi de $88,2 \%(\mathrm{~W}=772,5 ; \mathrm{p}=0,5475)$. Ao comparar a percepção de aprendizagem nos dois grupos utilizando o Mann-Whitney-Wilcoxon Test ao nível de significância de 0,05, percebeu-se uma diferença significativa entre as duas amostras $(\mathrm{W}=438 ; \mathrm{p}=0,001974)$ já que no grupo não observado 33,3\% optaram pelo nível 5 nesta questão e 38,1\% optaram pelo nível 4, $19 \%$ pelo nível 3,4,8\% pelo nível 2 e 4,8\% pelo nível 1 e no grupo observado obteve-se o resultado mostrado na Figura 8. Alguns fatores que podem ter influenciado esse resultado são: i) o fato de as atividades em sala de aula terem sido realizadas em equipes (geralmente duplas) e não individualmente; ii) a diferença na faixa etária entre os grupos; ou mesmo iii) a diferenciação do ambiente escolar tradicional que pode ter gerado uma maior percepção da aprendizagem nos alunos do que explorar individualmente o aplicativo em ambiente não formal de aprendizagem. Embora os resultados apresentados não possam ser generalizados devido ao tamanho das amostras, a experiência observada pode incentivar outras aplicações em ambiente escolar em que se explore o uso do aplicativo com os estudantes trabalhando em equipes, que é um dos trabalhos futuros propostos.

\subsection{Resultados da Entrevista com a Docente que Fez Parte do Estudo por Observação}

Ao fim de todas as aplicações nas 3 turmas, foi realizada uma pequena entrevista via aplicativo de troca de mensagens instantâneas com a professora que conduziu a aplicação das atividades em sala de aula. A entrevista completa foi transcrita e sua análise está apresentada a seguir.

As perguntas foram realizadas baseando-se no que foi observado em sala de aula durante o uso do aplicativo e servem para podermos enxergar pela ótica do professor como foi a experiência da aplicação.

Um ponto a destacar é a interação entre os participantes, tanto internamente entre os membros da equipe, como com a comunicação com outras equipes e que foi proporcionada pela experiência com o aplicativo. Com relação a isso, a professora fez a seguinte declaração:

"Uma coisa que eu sofro muito durante o ano letivo é para conseguir que os alunos trabalhem em equipe [...] e trabalho em equipe hoje é fundamental. Então, com a ajuda do aplicativo, da sua aplicação, eles acabaram trabalhando em conjunto "né", em grupo, de maneira transparente, "tipo", foi natural aquilo ali, e foi gratificante ver tanto as duplas interagindo, eles compartilharam mesmo, tanto quando alguma dupla terminava, ela já ia ajudar a dupla seguinte."

Outra pergunta relacionada é com relação à comemoração dos alunos ao finalizarem as atividades. Nesse sentido a professora respondeu:

"Eles estavam ali aprendendo com um tablet, então na cabecinha deles é como se eles estivessem jogando, e a sensação de ganhar é inigualável, então eles ficavam muito felizes, principalmente quando eles faziam as atividades sem erros". 
De fato, a sensação de vitória ao realizar um desafio é algo que instiga uma comemoração. No entanto, o fato dos alunos usarem os tablets por si só é uma injeção de curiosidade, pois chama a sua atenção. O ponto forte está na junção desses dois mundos, atividades que os desafiam e os motivam em dispositivos móveis que os atraem e lhes trazem feedback instantâneo.

Além disso, a professora reportou algumas melhorias que poderiam ser feitas no aplicativo, como redução dos textos e mudança no esquema de cores. Ela também informou que os níveis em que os alunos mais sentiram dificuldade foram o 3 e 7 . Por fim, manifestou interesse em utilizar o aplicativo em suas próximas versões em sala de aula de maneira efetiva, ressaltando que os alunos se envolveram muito na atividade mesmo não tendo contato prévio com o assunto, uma vez que se tratava da primeira aula da professora com as referidas turmas.

\section{Considerações Finais e Trabalhos Futuros}

Neste trabalho foram apresentadas avaliações do aplicativo "Computação Plugada". Pelos resultados deste estudo inicial, acredita-se que ele pode facilitar a aplicação e disseminação das atividades da computação desplugada com uma boa aceitação por professores e estudantes, apesar da quantidade de participantes do estudo.

De maneira geral, pode-se concluir que o aplicativo "Computação Plugada" foi bem aceito pelos professores e estudantes que participaram dos estudos, apesar de não se poder generalizar esse resultado pela quantidade pequena de participantes. Durante a observação da aplicação em sala de aula, foi possível identificar uma grande interação e motivação entre os alunos participantes. Um ponto negativo detectado está relacionado ao modo de interação com o usuário e que precisa de melhorias, assim como é preciso rever a paleta de cores na versão utilizada na avaliação.

Como trabalhos futuros, pretendem-se realizar outras avaliações com as novas versões do aplicativo que vêm sendo lançadas e propor novos aplicativos visando "plugar" outras atividades desplugadas tendo também como foco o feedback rápido e facilitar a aplicação das atividades. Pretende-se também realizar um estudo para verificar a eficiência do aplicativo no estímulo ao pensamento computacional bem como no auxílio ao desenvolvimento dos seus pilares. Outro trabalho futuro previsto é a análise mais profunda de melhorias de usabilidade no aplicativo, como a diminuição de textos e ajuste das cores utilizadas e avaliação com públicos de diferentes idades, como crianças de 7 anos. Acredita-se que também é um trabalho futuro interessante explorar o uso do aplicativo "Computação Plugada" como parte da aplicação da metodologia proposta no trabalho de Berto, Zaina e Zacata (2019) de alternância de atividades plugadas e desplugadas e envolvendo projetos. Outro trabalho futuro também é analisar em maior profundidade a exploração de aplicativos desta natureza por meio de atividades em duplas ou trios para identificar benefícios da aprendizagem colaborativa nesse contexto.

\section{Agradecimentos}

Agradecemos a todos os que avaliaram o aplicativo Computação Plugada Binários apresentado neste trabalho. Agradecemos também às sugestões dos revisores da RBIE e pelos comentários das professoras Thaíse Costa e Pasqueline Dantas Scaico e que ajudaram a enriquecer os resultados aqui apresentados. Nossa gratidão também ao apoio financeiro da Chamada n. 03/2020 Produtividade em Pesquisa PROPESQ/PRPG/UFPB, onde o projeto Computação Plugada está inscrito com o código PVP13499-2020 no SIGAA e a todos os que vêm dando continuidade ao trabalho aqui apresentado. 


\section{Referências}

Araújo, A. L., Andrade, W., \& Guerrero, D. (2016, November). Um mapeamento sistemático sobre a avaliaçao do pensamento computacional no Brasil. In Anais dos Workshops do Congresso Brasileiro de Informática na Educação (Vol. 5, No. 1, p. 1147). doi: 10.5753/cbie.wcbie.2016.1147 [GS Search]

Bell, T.; Witten, I. e Fellows, M. (2011). "Computer Science Unplugged - Ensinando Ciência da Computação sem o uso do Computador". Tradução de Luciano Porto Barreto, 2011. Disponível em: https://classic.csunplugged.org/wpcontent/uploads/2014/12/CSUnpluggedTeachers-portuguese-brazil-feb-2011.pdf

Bell, T., Alexander, J., Freeman, I., \& Grimley, M. (2009). Computer science unplugged: School students doing real computing without computers. The New Zealand Journal of Applied Computing and Information Technology, 13(1), 20-29. [GS Search]

Berto, L. M, Zaina, L. A. M. \& Sakata, T. C. (2019). Metodologia Para Ensino do Pensamento Computacional para Crianças Baseada na Alternância de Atividades Plugadas e Desplugada. Revista Brasileira de Informática na Educação - RBIE, 27(2), 01-22. doi: 10.5753/RBIE.2019.27.02.01 [GS Search]

Brackmann, C., Boucinha, R., Román-González, M., Barone, D. e Casali, A. (2017). Pensamento Computacional Desplugado: Ensino e Avaliação na Educação Primária da Espanha. Anais dos Workshops do Congresso Brasileiro de Informática na Educação, 6(1), 982. doi: 10.5753/cbie.wcbie.2017.982 [GS Search]

Bradley, M. M.; Lang, P. J. (1994) Measuring Emotion: The Self-Assessment Manikin and the Semantic Differential. In: J. Behav. Ther. \& Exp. Psychiat, v. 25, n. 1, p. 49-59. [GS Search]

Desmet, P.M.A., Overbeeke, C.J. \& Tax, S. J. E. T. (2001). Designing Products with Added Emotional Value: Development and Application of an Approach for Research through Design. The Design Journal, 4(1), 32-47. doi: 10.2752/146069201789378496 [GS Search]

IBGE (2016). Pnad Contínua. Acesso à Internet e à Televisão e Posse de Telefone Móvel Celular para Uso Pessoal: Análise dos Resultados. Disponível em: https://biblioteca.ibge.gov.br/visualizacao/livros/liv101705_informativo.pdf

Gibson, Ben; Bell, Tim. (2013) Evaluation of games for teaching computer science. In: Proceedings of the 8th Workshop in Primary and Secondary Computing Education. p. 51-60. doi: $10.1145 / 2532748.2532751$ [GS Search]

Gil, Antonio C. (2017). Como Elaborar Projetos de Pesquisa. 6. ed. Atlas.

Kafai, Y. and Burke, Q. (2014). Connected code: Why Children Need to Learn Programming. MIT Press. [GS Search]

Gutierrez-Aguilar, O; Salas-Valdivia, L. (2019) Collaborative Learning: The Educational Perspective of Facebook. In: 2019 XIV Latin American Conference on Learning Technologies (LACLO). IEEE, p. 348-352. doi: 10.1109/LACLO49268.2019.00065 [GS Search]

Moran, José Manoel. (2007). A Educação que Desejamos: novos desafios e como chegar lá. $5^{\text {a }}$ ed. Campinas. Papirus Educação. Disponível em: http://www2.eca.usp.br/moran/wpcontent/uploads/2017/11/tecnologias_moran.pdf

Netto, D., Medeiros, L., de Pontes, D. e de Morais, E. (2017). Game Logic: Um jogo para auxiliar na aprendizagem de lógica de programação. Anais do $25^{\circ} \mathrm{WEI}$ - Workshop sobre Educação em Computação. doi: 10.5753/wei.2017.3546 [GS Search] 
Oliveira Matheus; Dantas, Ayla; Gomes Neto, Ivonildo (2019). Computação Plugada: Um Aplicativo Android Para Apoiar a Aplicação de Exercícios de Computação Desplugada. In: Anais do XXVII Workshop sobre Educação em Computação. SBC. p. 493-502. doi: 10.5753/wei.2019.6654 [GS Search]

Pessoa, F. I. R, de Araújo, A. L. S. O, Andrade, W. L. e Guerrero, D. D. S. (2017). T-mind: um Aplicativo Gamificado para Estímulo ao Desenvolvimento de Habilidades do Pensamento Computacional. Anais do $28^{\circ}$ Simpósio Brasileiro de Informática na Educação, p. 645. doi: 10.5753/cbie.sbie.2017.645 [GS Search]

Pinho, G., Weisshahn, Y., de Brum, C. F., Cavalheiro, G. G. H., \& Cavalheiro, S. (2016). Proposta de Jogo Digital para Dispositivos Móveis: Desenvolvendo Habilidades do Pensamento Computacional. Anais do $27^{\circ}$ Simpósio Brasileiro de Informática na Educação, p. 100. doi: 10.5753/cbie.sbie.2016.100 [GS Search]

Rebouças, A. D.; Maia, D. L.; Scaico, P. D. (2021) Objetos de Aprendizagem: da Definição ao Desenvolvimento, Passando pela Sala de Aula. In: PIMENTEL, Mariano; SAMPAIO, Fábio F.; SANTOS, Edméa O. (Org.). Informática na Educação: ambientes de aprendizagem, objetos de aprendizagem e empreendedorismo. Porto Alegre: Sociedade Brasileira de Computação. (Série Informática na Educação, v.5) Disponível em: http://ieducacao.ceiebr.org/objetos-aprendizagem

Sandoval-Bringas, J. A.; Álvarez-Rodriguez, F. J.; Carrenõ-León, M. A. (2018) Analysis of the use of M-Learning environments in higher education from the perspective of students from the academic department of Computer Systems at the Autonomous University of Baja California Sur, Mexico. In: 2018 XIII Latin American Conference on Learning Technologies (LACLO). IEEE, p. 61-64. doi: 10.1109/LACLO.2018.00024 [GS Search]

Silva, G., Leite, L. e Jesus, A. (2018). As Aventuras de Ada e Turing: Apoiando o Desenvolvimento de Habilidades do Pensamento Computacional por Meio de um Jogo. Anais do $26^{\circ}$ Workshop sobre Educação em Computação (WEI). p. 382. Disponível em: http://natal.uern.br/eventos/csbc2018/anais/Anais\%20WEI\%202018.pdf

Silva, W. R. A.; Aguiar, Y. P.; Araújo, J. A. (2016) Avaliação Tridimensional Do Uso Do Scilab No Ensino De Matrizes. In: Nuevas Ideas en Informática Educativa (TISE 2016), Santiago. Nuevas Ideas en Informática Educativa (TISE 2016), 2016. v. 12. p. 495-500. Disponível em: http://www.tise.cl/volumen12/TISE2016/495-500.pdf

Silvestrin, R. (2018). Desplugado/Plugado: O que Desligar e o que Ligar em Termos de Educação. Disponível em: https://www.academia.edu/3811394/DESPLUGADO_PLUGADO_O_QUE_DESLIGAR_ E_O_QUE_LIGAR

Tajra, S. F. (2012). Informática na Educação: novas ferramentas pedagógicas para o professor na atualidade. 9a. ed. Editora Érica. [GS Search]

Wing, J. M. (2006). Computational thinking. Commun. ACM, 49(3):33-35. doi: 10.1145/1118178.1118215 [GS Search]

Wing, J. M. (2014) Computational Thinking Benefits Society. Social Issues in Computing. Disponível em: http://socialissues.cs.toronto.edu/2014/01/computational-thinking/ [GS Search]

Yadav, A., Stephenson, C., and Hong, H. (2017). Computational thinking for teacher education. Communications of the ACM, 60(4):55-62. doi: 10.1007/978-3-319-52691-1_13 [GS $\underline{\text { Search] }}$ 


\section{Apêndices}

\section{A. Formulário De Avaliação do App Computação Plugada Por Professores de Computação}

\section{Avaliação do APP Computação Plugada por Professores de Computação}

Olá, querido colaborador.

Esse formulário tem como objetivo coletar a opinião de professores de computação que já aplicaram atividades de computação desplugada quanto à utilização do aplicativo Computação Plugada como ferramenta instrucional para auxiliar no ensino.

Para responder o questionário é necessário que o colaborar obtenha e utilize o aplicativo em questão através do link:

<https://drive.google.com/file/d/1XpVZLtWJquTuTY6OctsCH46LCoM_ILqH/view?usp=sharing> O Aplicativo funciona em Dispositivos com sistema operacional Android 4.0 ou superior.

O link contém o arquivo instalador ".apk" do aplicativo. Você deve baixar e instalar. Pode ser necessário habilitar a instalação de aplicativos de fonte desconhecida, para isso acesse as configurações do seu dispositivo > segurança > habilitar fontes desconhecidas. Qualquer problema na instalação favor enviar e-mail para: matheus.barbosa@dce.ufpb.br

Os dados coletados com esse formulário serão utilizados na pesquisa do trabalho de conclusão de curso do aluno Matheus Barbosa de Oliveira, mas a identidade dos participantes será preservada. Solicito que as respostas sejam bem sinceras visando sempre melhorias no aplicativo que está sendo proposto.

Desde já agradecemos por sua valiosa contribuição.

*Obrigatório

\section{Termo de Consentimento}

É necessário que o colaborador concorde com a afirmação para que os dados coletados possam ser utilizados na pesquisa

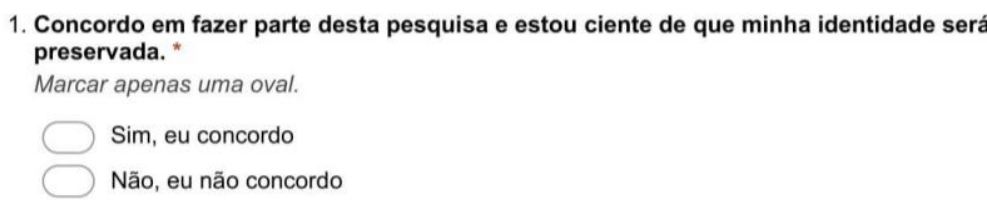

Marcar apenas uma oval.

Sim, eu concordo

Não, eu não concordo

Identificação do Colaborador

Seção destinada a obter dados sobre o colaborador e sua experiência

2. Qual o seu nome?

3. Em qual instituição você leciona? *

4. Há quanto tempo você exerce a profissão de professor na área de computação? *

Marcar apenas uma oval.

Há 2 anos ou menos

Há 5 anos ou menos e mais de 2 anos

Há 10 anos ou menos e mais de 5 anos

Há mais de 10 anos 
5. Quais disciplinas na área de computação você já lecionou ou está lecionando atualmente? *

6. O quanto você explorou o aplicativo Computação Plugada? * Marcar apenas uma oval.

Completei todos os niveis

Completei pelo menos metade dos níveis (Pelo menos até o nível 4 foi concluído)

Completei menos da metade dos níveis (Completei de 2 a 3 níveis)

Completei apenas 1 nível

Só olhei o aplicativo e não completei nenhum nível

\section{Avaliação do Aplicativo Computação Plugada}

O Aplicativo "Computação Plugada" baseia-se na ideia de "Plugar" as atividades da "Computação Desplugada". Algumas atividades foram adaptadas e disponibilizadas através de um aplicativo Android que pode ser obtido através do link:

<https://drive.google.com/drive/folders/19uA8RQvbBGznPPALQnDrkbW1VDmYV4WF?usp=sharing>

Caso ocorra algum problema na instalação, favor enviar e-mail para matheus.barbosa@dce.ufpb.br

É fundamental que você tenha instalado e utilizado o aplicativo antes de responder as questões a seguir e que você já tenha utilizado alguma atividade de computação desplugada com estudantes.

7. Com quais alunos você já aplicou atividades de computação desplugada? * Marque todas que se aplicam.
Com alunos da educação infantil
Com alunos do ensino fundamental
Com alunos do ensino médio ou técnico
Com alunos do ensino superior
Outro:

8. Que tipos de atividades de computação desplugada você já aplicou? * Marque todas que se aplicam.
Atividade de números binários do livro "Computação Desplugada" de Tim Bell
Outras atividades do livro "Computação Desplugada" de Tim Bell
Atividades do site http://csunplugged.com
Outro:

9. Você já realizou atividades utilizando Smartphone ou Tablets com seus alunos? * Marcar apenas uma oval.
Sim
Não 
10. Quão fácil você achou de usar o aplicativo "Computação Plugada" * Marcar apenas uma oval.

Muito Dificil

11. O quanto você concorda com a afirmação "Assumindo que há dispositivos disponíveis para os alonos, acredito que aplicar as atividades com o aplicativo Computação Plugada parece tornar mais simples a aplicação do que da forma convencional." *

Marcar apenas uma oval.

$\begin{array}{lllllll} & 1 & 2 & 3 & 4 & 5 & \\ \text { Discordo Totalmente } \square \longrightarrow C & \square & \end{array}$

12. Em uma escala de $\mathbf{0}$ a 10 , qual a chance de você indicar o App Computação Plugada para outras pessoas? *

Marcar apenas uma oval.

Nenhuma $\square$

13. Deixe aqui algum comentário, sugestão ou crítica ao aplicativo, explicitando os pontos negativos e positivos de se utilizá-lo em sala de aula. Seu feedback é muito importante.

Google Forms 


\section{B. Formulário De Avaliação do APP Computação Plugada Formulário De Avaliação do App Computação Plugada}

Olá, querido colaborador.

Esse formulário tem como objetivo coletar a opinião de usuários quanto aos Conceitos Aplicados, Usabilidade, Aparência e Desempenho do Aplicativo Computação Plugada.

Para responder o questionário é necessário que o colaborar obtenha e utilize o aplicativo em questão através do link:

$<$ https://drive.google.com/file/d/1XpVZLtWJquTuTY6OctsCH46LCoM_ILqH/view? usp=sharing>

O Aplicativo funciona em Dispositivos com sistema operacional Android 4.0 ou superior.

Os dados coletados com esse formulário serão utilizados na pesquisa do trabalho de conclusão de curso do aluno Matheus Barbosa de Oliveira, mas a identidade dos participantes será preservada. Solicito que as respostas sejam bem sinceras visando sempre melhorias no aplicativo que está sendo proposto.

Desde já agradecemos por sua valiosa contribuição.

*Obrigatório

\section{Identificação do Usuário}

Seção destinada para requisição dos dados do usuário

1. Concordo em fazer parte desta pesquisa e estou ciente de que minha identidade será preservada. *

Marcar apenas uma oval.

DSim

Não

2. Nome Completo

3. Idade: *

4. Sexo*

Marcar apenas uma oval.

Masculino

Feminino

Prefiro não identificar

5. Modelo do Aparelho utilizado para avaliação: 
6. O quanto você explorou o aplicativo Computação Plugada? *

Marcar apenas uma oval.

Completei todos os niveis

Completei pelo menos metade dos níveis (Nivel 5 ou superior)

Completei menos da metade dos niveis (Completei de 2 a 3 niveis)

Completei apenas 1 nivel

Só olhei o aplicativo e não completei nenhum nível.

7. Escolha a(s) opção(oeste) que mais se encaixam com você: *

Marque todas que se aplicam.
Professor na área de computação
Aluno de graduação na área de computação
Aluno de graduação de outra área
Aluno do ensino médio ou técnico
Aluno do ensino fundamental
Ex-aluno de graduação na área de computação
Outro:

\section{Conceitos Aplicados}

8. O quanto o aplicativo em si contribuiu para o seu aprendizado sobre números binários? * Marcar apenas uma oval.

$\begin{array}{llllll}1 & 2 & 3 & 4 & 5 & \\ \text { Contribuiu Pouco } & \square & \square & \\ & \square & & \end{array}$

9. Justifique sua escolha da questão anterior *

\section{Usabilidade}

Seção destinada a avaliar a experiência do aluno após as atividades utilizando o aplicativo

Computação Plugada, por meio do método de avaliação SAM - Self Assessment Manikin. A partir disso, será avaliado os sentimentos dos usuários voltados para a atividade aplicada por meio de figuras, utilizando uma escala variando de 1 à 9 , onde o número 5 que fica no centro dessa escala, será considerado que o usuário nem teve um sentimento muito negativo, nem muito positivo. 
10. Qual o seu grau de satisfação ao utilizar o aplicativo? *
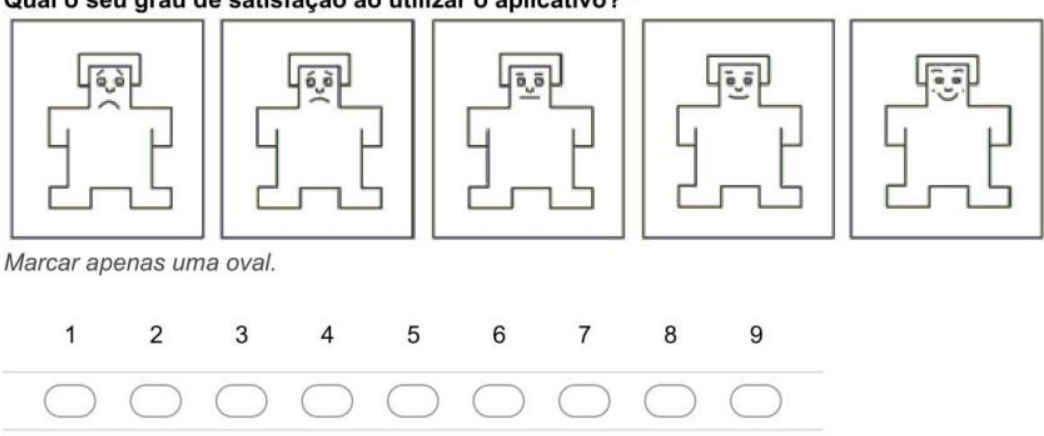

1. Qual o seu grau de motivação ao utilizar o aplicativo? *
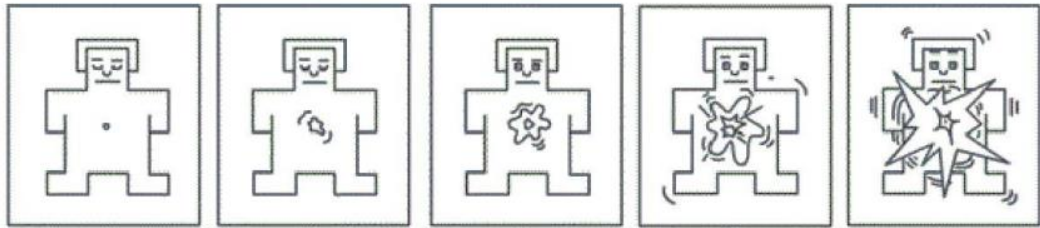

Marcar apenas uma oval.

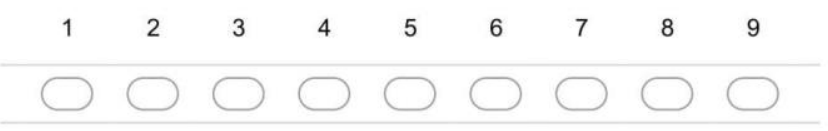

12. Qual foi o seu grau de controle ao utilizar o aplicativo? *

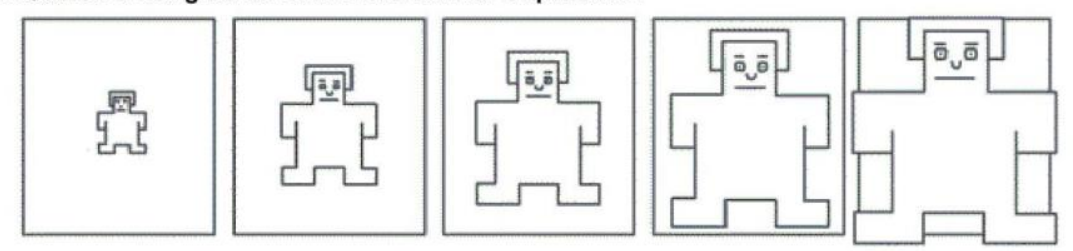

Marcar apenas uma oval.

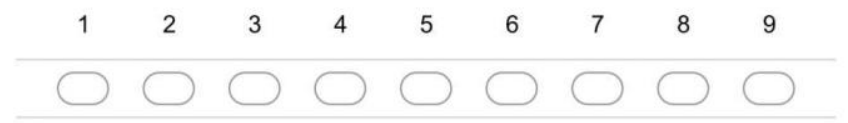

\section{Aparência}

Seção destinada à requisição dos dados do usuários com relação à apresentação visual do aplicativo

13. Visualmente, quanto que a Aparência do aplicativo te agrada? *

Marcar apenas uma oval.

$\begin{array}{lllll}1 & 2 & 3 & 4 & 5 \\ \text { Pouco } \square & \square & \square\end{array}$


14. O aplicativo apresenta alguma distorção no tamanho das imagens ou de algum componente das telas? Se sim, descreva o problema encontrado. *

15. O aplicativo apresenta algum erro de português? Se sim, descreva o problema encontrado. "

16. Quanto às cores utilizadas no aplicativo, o quanto elas te agradam? * Marcar apenas uma oval.

\begin{tabular}{|c|c|c|c|c|c|}
\hline & 2 & 3 & 4 & 5 & \\
\hline Pouco & & & & & Muito \\
\hline
\end{tabular}

17. Você tem alguma sugestão para melhoria da aparência do aplicativo? Qualquer dica vai ser lida e consultada pela equipe de desenvolvimento.

\section{Desempenho}

Seção destinada à requisição de dados sobre o desempenho do aplicativo.

18. O aplicativo apresentou algum problema de desempenho (lentidão, travamentos)? * Marcar apenas uma oval.
$\operatorname{Sim}$
Não

19. Se a resposta anterior for "Sim", justifique sua opinião descrevendo o que observou.

\section{Avaliação}

20. Em uma escala de 0 a 10, qual a chance de você indicar o App Computação Plugada para outras pessoas? *

Marcar apenas uma oval.

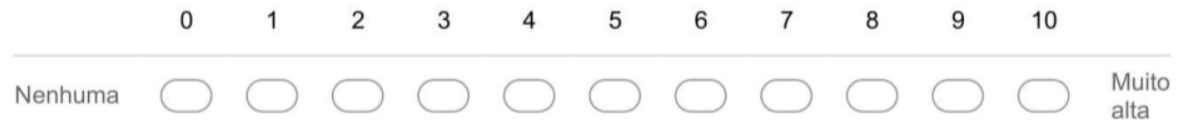




\section{Protocolo de observação}

\begin{tabular}{|c|c|c|c|c|c|}
\hline Data e Hora: & Professor: & \multicolumn{2}{|c|}{ Protocolo de Observação } & $\begin{array}{l}\text { Quantidade de } \\
\text { Participantes: }\end{array}$ & Turma: \\
\hline \multicolumn{6}{|c|}{ Aspectos Observados } \\
\hline \multirow{3}{*}{ Interesse } & \multicolumn{2}{|c|}{ Pedem ajuda do professor(a) ou monitor. } & Colaboração & \multicolumn{2}{|c|}{$\begin{array}{c}\text { Interagem entre si para resolver as } \\
\text { questōes }\end{array}$} \\
\hline & \multicolumn{2}{|c|}{ Prestaram atenção na explicação do professor } & \multirow{2}{*}{ Desinteresse } & \multicolumn{2}{|c|}{$\begin{array}{c}\text { Utilizam o dispositivo eletronico para } \\
\text { outra finalidade }\end{array}$} \\
\hline & \multicolumn{2}{|c|}{$\begin{array}{l}\text { Comemoram ou estão animados com a resolução dos } \\
\text { exercícios }\end{array}$} & & \multicolumn{2}{|c|}{ Conversam paralelamente } \\
\hline \multicolumn{6}{|c|}{$\begin{array}{ll}\text { Tempos das Atividades } \\
\end{array}$} \\
\hline & $30 \mathrm{~min}$ & $50 \mathrm{~min}$ & $60 \mathrm{~min}$ & $70 \mathrm{~min}$ & $80 \mathrm{~min}$ \\
\hline \multicolumn{6}{|l|}{ Nivel 1} \\
\hline \multicolumn{6}{|l|}{ Nivel 2} \\
\hline \multicolumn{6}{|l|}{ Nivel 3} \\
\hline \multicolumn{6}{|l|}{ Nivel 4} \\
\hline \multicolumn{6}{|l|}{ Nivel 5} \\
\hline \multicolumn{6}{|l|}{ Nivel 6} \\
\hline \multicolumn{6}{|l|}{ Nivel 7} \\
\hline \multicolumn{6}{|l|}{ Nivel 8} \\
\hline Terminou & & & & & \\
\hline
\end{tabular}




\title{
D. Roteiro da entrevista semiestruturada
}

\section{Planejamento Semiestruturado da Entrevista Com A \\ Docente Que Fez Parte do Estudo}

\author{
Apresentação \\ - Agradecimento ao participante \\ - Solicitação de entrevista
}

\section{Objetivo da Entrevista}

O objetivo desta pesquisa é entender pela ótica do professor como foi a experiência na utilização do aplicativo "Computação Plugada" em sala de aula, abordando aspectos observados durante a aplicação.

\section{Introdução}

O conteúdo das entrevistas será utilizado apenas para fins da pesquisa acadêmica, não tendo assim nenhuma influência na avaliação do professor perante o seu desempenho em suas atividades na disciplina. A entrevista será gravada para posterior documentação. Ao final da pesquisa, os dados serão publicados em eventos de natureza acadêmica, mas os nomes das pessoas envolvidas serão omitidos nas respectivas publicações. Sua participação nesta pesquisa é voluntária podendo-se decidir não participar ou se retirar da pesquisa a qualquer momento.

\section{Perguntas}

1. Conseguimos perceber durante a observação que alguns alunos recorreram a você para tirar dúvidas. O que você pode ser dito sobre essas dúvidas dos alunos? É mais em alguns exercícios específicos? Qual o nível de dificuldade deles? Eles prestavam atenção na explicação?...

2. Outra coisa que conseguimos notar é que alguns alunos comemoravam ao terminar as atividades. Você também percebeu isso?

3. Um dos pontos mais fortes identificados foi a interação entre os alunos. Acredito que isso também tenha sido observado por você, fale um pouco sobre isso, essa interação que os alunos tiveram entre membros da própria dupla/trios, e entre outras duplas/trios.

4. Todos os alunos conseguiram terminar as atividades, mas alguns demoraram um pouco mais, o que você acha que pode ter acontecido que contribuiu para a demora de uns alunos mais do que outros?

5. Em algum momento, você percebeu os alunos utilizando o tablet para outras finalidades sem ser o aplicativo?

6. Por fim, gostaríamos que você deixasse um feedback geral do que foi essa experiência na utilização do aplicativo em sala de aula. Foi fácil aplicar? Pode ser útil em outras turmas? Dê a sua opinião. 


\section{E. Resultado da Avaliação SAM dos Alunos}

\begin{tabular}{|c|c|c|c|c|}
\hline \multicolumn{5}{|c|}{ SAM } \\
\hline Colaborador & Satisfação & Motivação & Controle & Total \\
\hline 1 & 4 & 9 & 9 & 72 \\
\hline 2 & 4 & 9 & 9 & 72 \\
\hline 3 & 4 & 9 & 9 & 72 \\
\hline 4 & 4 & 8 & 7 & 60 \\
\hline 5 & 4 & 9 & 9 & 72 \\
\hline 6 & 2 & 9 & 9 & 36 \\
\hline 7 & 4 & 9 & 9 & 72 \\
\hline 8 & 4 & 8 & 9 & 68 \\
\hline 9 & 2 & 9 & 9 & 36 \\
\hline 10 & -3 & 8 & 9 & -51 \\
\hline 11 & 4 & 9 & 9 & 72 \\
\hline 12 & 4 & 9 & 9 & 72 \\
\hline 13 & 3 & 8 & 8 & 48 \\
\hline 14 & 0 & 3 & 7 & 0 \\
\hline 15 & 4 & 9 & 9 & 72 \\
\hline 16 & 3 & 7 & 7 & 42 \\
\hline 17 & 4 & 9 & 9 & 72 \\
\hline 18 & 4 & 9 & 9 & 72 \\
\hline 19 & 3 & 9 & 9 & 54 \\
\hline 20 & 4 & 8 & 9 & 68 \\
\hline 21 & 3 & 2 & 9 & 33 \\
\hline 22 & 4 & 8 & 9 & 68 \\
\hline 23 & 4 & 8 & 8 & 64 \\
\hline 24 & 2 & 8 & 9 & 34 \\
\hline 25 & 4 & 5 & 7 & 48 \\
\hline 26 & 3 & 8 & 7 & 45 \\
\hline 27 & 2 & 7 & 7 & 28 \\
\hline 28 & 2 & 4 & 7 & 22 \\
\hline 29 & 4 & 9 & 9 & 72 \\
\hline 30 & 4 & 7 & 6 & 52 \\
\hline 31 & 3 & 8 & 5 & 39 \\
\hline 32 & 1 & 8 & 8 & 16 \\
\hline 33 & 1 & 6 & 6 & 12 \\
\hline 34 & 0 & 5 & 4 & 0 \\
\hline 35 & 3 & 8 & 7 & 45 \\
\hline 36 & 4 & 9 & 7 & 64 \\
\hline 37 & 4 & 9 & 9 & 72 \\
\hline 38 & 2 & 7 & 7 & 28 \\
\hline 39 & 1 & 6 & 6 & 12 \\
\hline 40 & 4 & 9 & 9 & 72 \\
\hline 41 & 4 & 9 & 6 & 60 \\
\hline 42 & 1 & 7 & 3 & 10 \\
\hline 43 & 4 & 9 & 9 & 72 \\
\hline 44 & 4 & 9 & 9 & 72 \\
\hline
\end{tabular}

\begin{tabular}{|c|c|c|c|c|}
\hline 45 & 4 & 9 & 9 & 72 \\
\hline 46 & 4 & 8 & 8 & 64 \\
\hline 47 & 2 & 5 & 4 & 18 \\
\hline 48 & 4 & 9 & 8 & 68 \\
\hline 49 & 4 & 9 & 9 & 72 \\
\hline 50 & 2 & 7 & 7 & 28 \\
\hline 51 & 4 & 9 & 7 & 64 \\
\hline 52 & 5 & 7 & 6 & 65 \\
\hline 53 & 4 & 8 & 8 & 64 \\
\hline 54 & 1 & 7 & 7 & 14 \\
\hline 55 & 4 & 9 & 7 & 64 \\
\hline 56 & 4 & 9 & 9 & 72 \\
\hline 57 & 3 & 7 & 7 & 42 \\
\hline 58 & 4 & 9 & 9 & 72 \\
\hline 59 & 1 & 7 & 7 & 14 \\
\hline 60 & 2 & 5 & 8 & 26 \\
\hline 61 & 4 & 9 & 9 & 72 \\
\hline 62 & 4 & 5 & 9 & 56 \\
\hline 63 & 4 & 9 & 8 & 68 \\
\hline 64 & 4 & 9 & 9 & 72 \\
\hline 65 & 3 & 8 & 7 & 45 \\
\hline 66 & 4 & 9 & 9 & 72 \\
\hline 67 & 4 & 9 & 8 & 68 \\
\hline 68 & 3 & 6 & 1 & 21 \\
\hline
\end{tabular}

